Reprod. Nutr. Dévelop., 1981, 21 (5 B), 815-847.

\title{
Contribution du gros intestin à la digestion des glucides et des matières azotées chez le monogastrique omnivore
}

par Alain RÉRAT

Laboratoire de Physiologie de la Nutrition
INRA-CNRZ. 78350 jouy-en-josas (France).

Summary. Contribution of the large infestine to the digestion of carbohydrates and profeins in omnivorous simple-sfomached animals.

Owing to its special situation in relation to the rest of the digestive tract, the large intestine may contribute considerably to the digestion of food and the absorption of nutrients. Because of the more or less long statis occurring there, due to an increase in digestive tract volume which creates true reservoirs, all the conditions favourable to intense microbial growth are combined in the large intestine. This paper examines some aspects of such microbial activity, particularly those concerning the breakdown of protein and carbohydrate residues which may arrive there. Some important aspects, such as metabolization of sterols and lipids by digestive flora, possible synthesis and absorption of vitamins $B$ and $K$ and the movements of water and electrolytes, have not been discussed.

The importance of the role of the large intestine in digestion depends on whether carbohydrates or proteins are involved, and it appears to be more efficient for the former than for the latter. In fact, whether we are studying cellulose or diholosides, whose undigested residues may arrive in large amounts in the large intestine due to their excessive proportion in the diet, a more or less marked bacterial breakdown is observed which produces volatile fatty acids. This method of recovery is quite efficient since those products are absorbed and utilized with a good metabolic yield. However, the breakdown is also characterized by the appearance of unusable wastes such as carbonic acid, hydrogen and methane which decrease the yield of carbohydrate breakdown. It should be emphasized that, at the present time, we have only a vague idea as to how these different products are formed, and that it is imperative to clarify this matter.

The breakdown of undigested carbohydrates leads to the appearance of various products, but it also produces energy for microbial synthesis. This microbial protein synthesis occurs at the expense of undigested nitrogenous matter of dietary or endogenous origin, arriving at that level. This nitrogenous matter, and particularly that of endogenous origin, is broken down and its amino acids deaminated or decarboxylated (formation of amines). The ammonia produced is re-utilized for microbial synthesis and excreted in the faeces in the form of microbial proteins, or absorbed and generally hardly used in the organism to synthesize non-essential amino acids. However, this process may be a good way of recycling endogenous nitrogen in adult animals which have only a maintenance requirement.

Anyway, the disappearance from the hindgut of either carbohydrates or nitrogenous matter represents 10 to $20 \mathrm{p}$. 100 of all the absorption processes throughout the digestive tract. Nitrogen excretion in microorganisms is usually directly related to the presence and the amount in the diet of poorly digestible carbohydrates or of cellulose. If we consider the low metabolic utilization of nitrogenous matter absorbed in the large intestine and the variation of its composition due to carbohydrates, the scientific and practical meaning of total protein digestibility should be discussed. It must be pointed out that the availability of 
amino acids, deduced from digestibility data, is usually overestimated, the error varying with the amino acid studied. A question still persists concerning the importance of the process of coprophagy in the re-utilization of microbial proteins.

\section{Introduction.}

Le gros intestin, en raison de sa situation anatomique distale relativement au reste du tube digestif, du volume et de la longueur de ses réservoirs, constitue une entité présentant des fonctions particulières dans la digestion, la sécrétion et l'absorption.

Il arrive au niveau de cet organe des contenus complexes provenant des parties antérieures du tube digestif et formés de résidus alimentaires non digérés, d'apports endogènes (desquamations et sécrétions) ef de microorganismes; il s'y ajoute au niveau de l'organe même des sécrétions. Ces matériaux constituent des substrats azotés, énergétiques et minéraux à haute teneur en humidité, très favorables au développement intense d'une microflore active. Celle-ci est susceptible de dégrader les substrats qui lui sont offerts à l'aide de ses enzymes qui viennent compléfer l'action rémanente possible des enzymes de l'intestin grêle, en l'absence de productions enzymatiques importantes au niveau du gros intestin (lsshiki et al., 1974). Par ailleurs, il se produit dans le gros intestin une absorption nette d'eau et de substances solubles (électrolytes), reliquats de la digestion des segments antérieurs ou produits de l'hydrolyse locale.

Le gros intestin est donc le lieu d'une série de remaniements liés à l'addition ou à la soustraction de divers principes alimentaires et substances chimiques. L'imporiance de ces remaniements est évidemment fonction du temps de séjour des contenus digestifs à ce niveau et du volume des réservoirs. Ces facteurs conditionnent la durée d'action de la flore et l'importance des surfaces d'absorption et de sécrétion. Il existe à ce sujet de très grandes variations interspécifiques, aussi bien du point de vue anatomique (Simic et llic, 1976) qu'au ṕlan de la durée de transit (Hill, 1969 ; Hecker et Grovum, 1975). Ainsi, le gros intestin, relativement très peu développé chez les oiseaux domestiques, espèces à transit rapide, est plus volumineux chez les mammifères et l'importance des réservoirs postérieurs tehd à s'accroître avec les fendances herbivores de l'espèce considérée : elle augmente depuis les rongeurs omnivores (Rat, Souris) jusqu'au Cheval en passant par des intermédiaires (Homme et Porc). On ne peut s'attendre à ce que la signification nutritionnelle du gros intestin et plus particulièrement de la flore qu'il héberge soił la même d'une espèce à l'autre en raison de ces différences.

Des revues ont déjà été consacrées au métabolisme des lipides et stérols (Eyssen, 1973 ; Combe ef al., 1976), aux mouvements des électrolytes et de l'eau (Cummings, $1975 a, b)$ ef aux vitamines du groupe B (Rérat, 1964, 1981 ; Hotzel et Barnes, 1966). Cette revue ne concernera donc que la digestion des protéines et des sucres.

\section{Digestion des glucides dans le gros intestin et absorption des produits de dégradation.}

On sait que les glucides présentent une digestibilité variable, non seulement selon leur nature (cellulose, amidon, etc...) mais également pour chaque famille de consti- 
tuants selon leur origine (pour la cellulose : paille, bois, etc...). Cetle variabilité signifie que les reliquats de la digestion dans l'intestin grêle passant la jonction iléo-cæcale sont très variabbles en quantité et en nature selon la composition chimique des glucides du régime.

\subsection{Dégradation des diverses familles de glucides dans le gros intestin.}

1.1.1. Glucides simples. - Les glucides les plus simples peuvent être mal digérés dans l'intestin grêle. Si la presque totalité du glucose ingéré disparaît au cours du transit dans l'intestin grêle, par contre la digestibilité iléale varie entre 72 et 95 p. 100 pour le saccharose ef 33 à 63 p. 100 pour le lactose selon la dose ingérée (Cunningham, Friend et Nicholson, 1963). Cette digestion insuffisante est liée au fait que les quantités reçues par l'animal ne sont pas adaptées à son potentiel enzymatique, variable selon l'âge et selon l'enzyme (Aumaitre, 1971 ; Manners, 1976). Ainsi, à l'inverse du saccharose, mal supporté par les animaux jeunes qui ne disposent pas suffisamment d'invertase (Dahlquist, 1961 ; Kidder et Manners, 1978), le lactose est bien utilisé chez le jeune animal puisque l'activité lactasique est très haute à la naissance et décroît rapidement jusqu'à 3 ou 4 semaines chez le Rat (Koldovsky et Chytil, 1965) et le Porc (Bailey, Kitts et Wood, 1956 ; Manners et Stevens, 1972 ; Ekstrom, Benevenga et Grummer, 1975b), et jusqu'à 3 ans chez l'Enfant (Cook, 1967). Il en résulte que le lactose est mal utilisé, passé un certain âge et chez certaines races (Ekstrom, Benevenga ef Grummer, 1975a), lorsqu'il est introduit dans le régime au-delà d'une certaine proportion, beaucoup plus forte chez le Porc que chez le Rat (Février, 1969 ; Shearer et Dunkin, 1968a). Il se produit alors une augmentation marquée du volume du gros intestin (Février, Collet et Bourdon, 1973 ; Shearer et Dunkin, 1968b) et de faibles quantités de sucres réducteurs sont présentes dans les fèces et surtout dans l'urine (Shearer et Dunkin, 1969). Malgré l'insuffisance de la production de lactase par l'animal, le lactose est donc dégradé et les produits de la dégradation sont absorbés. Ce fait est lié à l'apparition dans ces conditions d'une activité lactasique (Ekstrom, Benevenga et Grummer, 1975a ; Kim, Benevenga et Grummer, 1978a) au niveau du gros intestin ; contrairement à ce qui se passe dans l'intestin grêle, cette activité est présente dans les contenus et non dans la muqueuse (Aumaitre, Février ef Dewulf, 1977), ce qui laisse à penser que l'adaptation au lactose n'est pas le fait de l'animal, mais celui de la microflore. Ces résultats confirment l'utilité de la microflore pour la digestion du lactose chez le Porcelet (Schaffer ef al., 1965) et le Poulet (Siddons et Coates, 1972) démontrée à l'aide de la comparaison entre animaux axéniques et conventionnels ; ils vont à l'encontre des résultats obtenus sur le Rat par Reddy et Wostmann (1966), Reddy, Pleasants ef Wostmann (1968). Il s'agit là probablement de différences spécifiques liées au niveau d'activité lactasique propre à ces espèces.

1.1.2. Dégradation des amidons dans le gros intestin. - Les amidons dont une partie est déjà dégradée dans l'estomac sont presque entièrement digérés dans l'intestin grêle. Leur dégradation à ce niveau est cependant variable selon un certain nombre de facteurs physiologiques (âge) ou alimentaires (origine ou traitement technologique) (revue de Rérat, 1978).

De la dégradation incomplète de certains types d'amidon dans l'intestin grêle, notamment ceux de l'orge et du sorgho (Keys et de Barthe, 1974b), de l'amidon de 
pomme de terre (Mason ef Just, 1976), de l'amidon de maïs en grains conservés selon certains procédés (Holmes, Bayley et Horney, 1973 ; Bayley, Holmes ef Stevenson, 1974), résulte l'arrivée de contenus plus ou moins riches en substrats glucidiques au niveau du gros intestin. C'est ainsi que s'accumulent dans le cæcum des granules d'amidon cru de pomme de terre qui sont alors attaqués par les microorganismes (Baker et al., 1950).

Les microorganismes responsables de la dégradation de l'amidon dans le cæcum appartiennent principalement à une souche de Clostridium bufyricum (Baker ef al., 1950) qui représente la source principale d' $\alpha$-amylase trouvée dans le cæcum (Whelan et Nasr, 1951), cefte enzyme dégradant les amidons à raison de 65 p. 100 jusqu'au stade de maltose et de maltotriose. D'autres microorganismes sont présents dans le caecum, du groupe des lactobacilles et entérocoques, qui dégradent les premiers produits d'hydrolyse (maltose et dextrines) en hexoses, puis en acides pyruvique et lactique. Ces produits sont eux-mêmes dégradés par Cl. butyricum et un certain nombre de souches bactériennes présentes dans le cæcum, avec apparition d'acides gras volatils (Baker et al., 1950).

La digestibilité partielle iléorectale des amidons de diverses origines a été mesurée à l'aide de la technique des canules réentrantes de l'iléon chez le Porc. Pour Keys (1972), Keys et de Barthe (1974b), la digestibilité globale des amidons de blé ef de maïs est élevée (environ 98,5 p.100) : soit 3 (blé) à 5 (maïs) points de plus que la digestibilité iléale ; par contre, la digestibilité globale des amidons de mil et d'orge esi plus faible (environ 94 p. 100) et est supérieure de 8 points (mil) à 14 points (orge) à la digestion iléale (tabl. 1). Le gros intestin n'a pourtant qu'une importance réduite dans la digestion des céréales, en comparaison avec ce qui se passe pour l'amidon

TABLEAU 1

Coefficients de digestibilité $\left({ }^{a}\right)$ des glucides chez le porc nourri de blé, de mil, de mais et d'orge

\begin{tabular}{|c|c|c|c|c|c|c|}
\hline \multirow{2}{*}{ Item } & \multicolumn{4}{|c|}{ Traitement } & \multirow{2}{*}{$\begin{array}{l}\text { Ecart } \\
\text { type }\end{array}$} & \multirow{2}{*}{$\begin{array}{l}\text { Signification } \\
\text { statistique }\end{array}$} \\
\hline & Blé & Mil & Maïs & Orge & & \\
\hline \multicolumn{7}{|l|}{ Amidon } \\
\hline $\begin{array}{l}\text { Duodenum }(b) \ldots \ldots \ldots \ldots \\
\text { lleum }\left(^{b}\right) \ldots \ldots \ldots \ldots \ldots \ldots \\
\text { Feces }\left({ }^{c}\right) \ldots \ldots \ldots \ldots \ldots\end{array}$ & $\begin{array}{l}75,72 \\
94,97 \\
98,46\end{array}$ & $\begin{array}{l}63,27 \\
86,90 \\
94,66\end{array}$ & $\begin{array}{l}71,83 \\
93,36 \\
98,65\end{array}$ & $\begin{array}{l}45,11 \\
79,14 \\
93,57\end{array}$ & $\begin{array}{l}4,86 \\
5,09 \\
0,81\end{array}$ & $\begin{aligned} P<0,05 \\
N . S . \\
P<0,01\end{aligned}$ \\
\hline \multicolumn{7}{|l|}{ Amylose } \\
\hline $\begin{array}{l}\text { Duodenum }(b) \ldots \ldots \ldots \ldots \\
\text { lleum }(b) \ldots \ldots \ldots \ldots \ldots \\
\text { Feces }\left({ }^{(c)} \ldots \ldots \ldots \ldots \ldots\right.\end{array}$ & $\begin{array}{l}95,95 \\
97,53 \\
98,62\end{array}$ & $\begin{array}{l}90,05 \\
91,43 \\
94,49\end{array}$ & $\begin{array}{l}94,30 \\
96,61 \\
98,44\end{array}$ & $\begin{array}{l}69,37 \\
85,28 \\
93,59\end{array}$ & $\begin{array}{l}4,07 \\
4,42 \\
0,86\end{array}$ & $\begin{aligned} P & <0,05 \\
& N . S . \\
P & <0,05\end{aligned}$ \\
\hline \multicolumn{7}{|l|}{ Amylopectine } \\
\hline $\begin{array}{l}\text { Duodenum }(b) \ldots \ldots \ldots \ldots \\
\text { Ileum }(b) \ldots \ldots \ldots \ldots \ldots \\
\text { Feces }(c) \ldots \ldots \ldots \ldots\end{array}$ & $\begin{array}{l}70,45 \\
94,30 \\
98,41\end{array}$ & $\begin{array}{l}52,20 \\
86,06 \\
94,70\end{array}$ & $\begin{array}{l}66,52 \\
92,68 \\
98,67\end{array}$ & $\begin{array}{l}40,24 \\
77,74 \\
93,57\end{array}$ & $\begin{array}{l}7,66 \\
5,33 \\
0,80\end{array}$ & $\begin{array}{l}\text { N.S. } \\
\text { N.S. } \\
P<0,01\end{array}$ \\
\hline
\end{tabular}

(Keys et de Barthe, 1974b)

${ }^{(a)}$ Moyenne des 4 données ; $\left({ }^{b}\right)$ déterminée par l'usage d'un marqueur $\left(\mathrm{Cr}_{2} \mathrm{O}_{3}\right) ;\left({ }^{c}\right)$ déterminée par une collecte totale. 
de pomme de terre (Mason et Just, 1976) : ainsi, après ingestion d'amidon de pomme de terre, environ 19 p. 100 de l'énergie digestible disparaît dans le gros intestin, la valeur correspondante pour l'amidon de maïs étant de 9 p. 100 : l'énergie mise à la disposition de l'organisme provient ainsi en proportions différentes de la digestion enzymatique ef de la digestion microbienne selon l'origine botanique de l'amidon.

1.1.3. Dégradation des produits cellulosiques dans le gros intestin. - En l'absence de cellulase dans l'arsenal enzymatique du tube digestif chez les mammifères (cf. Mangold, 1934), la digestibilité de la cellulose brute chez le Porc varie pourtant entre 0 (Mitchell et Hamilton, 1933) ef 97 p. 100 (Poïjarvi, 1944). Son facteur principal de variation est lié à l'origine de la cellulose et aux traitements chimiques qu'elle a subis (cf. revue de Rérat, 1978) en raison de la proportion très variable de ses divers constituants, présentant eux-mêmes de très larges écarts de digestibilité (Laurentowska, 1959 ; Keys ef al., 1970). Il faut souligner que, malgré l'amélioration des techniques de dosage des produits cellulosiques (van Soest, 1973), les résultats qu'elles fournissent varient selon la procédure utilisée (Heller, Rivers et Hackler, 1977). Ceci peut comporter des conséquences importantes sur les données de digestibilité des diverses fractions cellulosiques et leur signification physiologique.

Par ailleurs, la digestibilité de la cellulose est susceptible de varier, dans une moindre mesure, sous l'influence de divers facteurs : facteur individuel, poids vif, taux d'introduction dans le régime, alimentation rationnée ou libérale, présence de hautes feneurs en certains sucres relativement peu digestibles comme le lactose (cf. revue de Rérat, 1978). La dégradation de la cellulose est certainement liée à l'action de la flore puisque sa digestibilité chez le Porc diminue lors de l'administration de sulfamides; une diminution de la dégradation par les antibiotiques estégalement montrée in vivo et in vitro.

La dégradation des produits cellulosiques dans les diverses sections du fube digestif a été bien mise en évidence chez le Porc par la technique des prélèvements iléaux d̀ l'aide de canules réentrantes iléocaecales (Keys, 1972 ; Keys et de Barthe, 1974a) (tabl. 2).

En général, la digestion de la cellulose et des hémicelluloses des parois cellulaires est négative dans l'intestin grêle, à l'exception notable de « coastal bermuda grass». Cetfe digestibilifé négative correspond probablement à un transit plus lent de ces substances qui s'accumulent ainsi dans le grêle durant le temps de la mesure ; il s'agit ainsi d'un artefact expérimental. Les travaux plus récents de Sambrook (1979) sur des régimes moins fortement cellulosiques mettent en évidence une dégradation marquée de ces matériaux (ADF) dans la deuxième partie de l'intestin grêle, la nature des matériaux cellulosiques intervenant sur leur degré de dégradation ; à cet égard, la cellulose purifiée subit une dégradation initiale plus faible que la cellulose contenue dans le tourteau d'arachide, mais serait ensuite plus complètement dégradée (van Soest, 1973).

En fait, la plus grande fraction des matëriaux cellulosiques est dégradée dans l'intestin postérieur (Trautmann et Asher, 1941, 1942), ce phénomène étant variable selon leur origine (Sambrook, 1979 ; Horszczaruk et Sljivovacki, 1966, 1971). Keys et de Barthe (1974a) montrent notamment que pour la luzerne, le sorgho et le « Texas Kleingrass », respectivement 100 p. 100 et 80 p. 100 de la digestion de la cellulose ef 
TABLEAU 2

Coefficients de digestibilité ${ }^{(a)}$ de la matière sèche et des constituants membranaires à partir d'échantillons prélevés dans le duodénum, l'iléon ef les fèces de porcs nourris de 4 régimes à base de foin

\begin{tabular}{|c|c|c|c|c|c|}
\hline \multirow[b]{2}{*}{ Item } & \multicolumn{4}{|c|}{ Traitement } & \multirow[b]{2}{*}{$\begin{array}{l}\text { Signification } \\
\text { statistique }\end{array}$} \\
\hline & Luzerne & Sorgho & $\begin{array}{c}\text { Texas } \\
\text { Kleingrass }\end{array}$ & $\begin{array}{l}\text { Coastal } \\
\text { Bermuda } \\
\text { grass }\end{array}$ & \\
\hline \multicolumn{6}{|l|}{ Matière sèche } \\
\hline 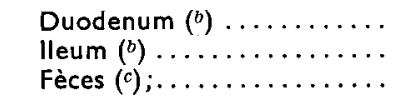 & $\begin{array}{r}8,12 \\
38,80 \\
68,21\end{array}$ & $\begin{array}{r}-13,12 \\
41,29 \\
70,50\end{array}$ & $\begin{array}{r}9,90 \\
37,77 \\
66,30\end{array}$ & $\begin{array}{r}-15,90 \\
46,60 \\
75,37\end{array}$ & $\begin{array}{l}\text { N.S. } \\
\text { N.S. } \\
P<0,05\end{array}$ \\
\hline \multicolumn{6}{|l|}{ Constituants membranaires } \\
\hline $\begin{array}{l}\text { Duodenum }\left({ }^{b}\right) \ldots \ldots \ldots \ldots \ldots \\
\text { lleum }\left(^{b}\right) \ldots \ldots \ldots \ldots \ldots \ldots \ldots \ldots \\
\text { Fèces }\left({ }^{c}\right) \ldots \ldots \ldots \ldots \ldots \ldots\end{array}$ & $\begin{array}{r}-4,69 \\
-\quad 4,62 \\
31,98\end{array}$ & $\begin{array}{r}6,43 \\
-\quad 3,56 \\
31,24\end{array}$ & $\begin{array}{r}-\quad 2,33 \\
-\quad 6,32 \\
21,61\end{array}$ & $\begin{array}{r}3,84 \\
39,42 \\
49,81\end{array}$ & $\begin{array}{l}\text { N.S. } \\
\text { N.S. } \\
P<0.01\end{array}$ \\
\hline \multicolumn{6}{|l|}{ Cellulose } \\
\hline 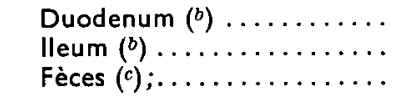 & $\begin{array}{r}2,93 \\
-\quad 8,80 \\
37,88\end{array}$ & $\begin{array}{r}8,65 \\
-\quad 8,24 \\
32,87\end{array}$ & $\begin{array}{r}4,46 \\
-\quad 6,67 \\
20,80\end{array}$ & $\begin{array}{r}9,66 \\
32,77 \\
47,75\end{array}$ & $\begin{array}{l}\text { N.S. } \\
\text { N.S. } \\
P<0,01\end{array}$ \\
\hline \multicolumn{6}{|l|}{ Hémicellulose } \\
\hline 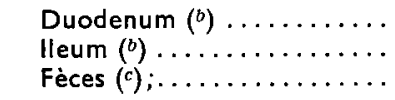 & $\begin{array}{l}17,19 \\
10,48 \\
33,41\end{array}$ & $\begin{array}{r}10,11 \\
4,24 \\
32,05\end{array}$ & $\begin{array}{r}0,93 \\
4,99 \\
25,32\end{array}$ & $\begin{array}{l}19,85 \\
47,47 \\
54,28\end{array}$ & $\begin{array}{l}\text { N.S. } \\
P \quad 0,05 \\
P<0,01\end{array}$ \\
\hline
\end{tabular}

(Keys and de Barthe, 1974a).

(a) Chaque coefficient est la moyenne de 4 valeurs; $\left({ }^{b}\right)$ Détermination grâce à l'oxyde de chrome ; (c) Détermination à partir de collecte totale.

des hémicelluloses sont effectués dans le gros intestin. Cette fraction est cependant variable selon l'origine des matériaux cellulosiques puisque dans le cas de «Coastal Bermuda grass », dont les constifuants cellulosiques présentent une digestibilité totale beaucoup plus élevée (environ 50 p. 100), 30 p. 100 des phénomènes de dégradation atteignant la cellulose le font dans le gros intestin, contre 13 p. 100 pour les hémicelluloses.

1.2. Les produits formés lors de la dégradation microbienne des glucides dans le gros intestin.

Simultanément à la dégradation des diverses familles de glucides apparaissent dans l'intestin les produits de dégradation enzymatique - le glucose notamment dont la digestion a été analysée antérieurement - et microbienne. La dégradation microbienne des glucides complexes (cellulose : Vartiovaara et Roine, 1942 ; amidon : Baker ef al., 1950) ou plus simples (glucose : Michel, 1961 b; 1965) conduit à la formation d'acides organiques et d'acide carbonique. La fermentation est également à l'origine d'autres composés tels que le méthane ou l'hydrogène (Levitt ef al., 1974).

La concentration des acides organiques évolue tout au long du tube digestif: chez le Porc (tabl. 3), au niveau de l'estomac elle est faible, l'acide lactique en consti- 
tuant presque la moitié (Alexander et Davies, 1963 ; Clemens, Stevens ef Southworth, 1975 ; Etienne, 1969 ; Cranwell et al., 1976) ; leur concentration reste faible dans l'intestin grêle (Etienne, 1969 ; Friend, Cunningham et Nicholson, 1963a) ; elle s'accroît faiblement dans la partie postérieure de l'intestin grêle (Sambrook, 1979), brutalement dans le cæcum (Ludvigsen et Thorbek, 1961) et dans le côlon où se ralentił considérablement le transit (Clemens, Stevens et Southworth, 1975).

\section{TABLEAU 3}

Pourcentages molaires des différents acides organiques dans le tube digestif du porc (moyenne de 10 animaux)

\begin{tabular}{|c|c|c|c|c|c|c|}
\hline Acides & Estomac & $\begin{array}{c}\text { Intestin } \\
\text { grêle } \\
\text { 1 re partie }\end{array}$ & $\begin{array}{c}\text { Intestin } \\
\text { grêle } \\
2^{\mathrm{e}} \text { partie }\end{array}$ & Cæcum & $\begin{array}{l}\text { Côlon } \\
\text { proximal }\end{array}$ & $\begin{array}{l}\text { Côlon } \\
\text { distal }\end{array}$ \\
\hline $\begin{array}{l}\text { Acetique } \ldots \ldots \ldots \ldots \ldots \\
\text { Propionique } \ldots \ldots \ldots \ldots \ldots \\
\text { Isobutyrique } \ldots \ldots \ldots \ldots \ldots \\
\text { Butyrique } \ldots \ldots \ldots \ldots \ldots \\
\text { Isovalérique } \ldots \ldots \ldots \ldots \ldots \\
\text { Valérique } \ldots \ldots \ldots \ldots \ldots \ldots \\
\text { Lactique } \ldots \ldots \ldots \ldots \ldots \ldots\end{array}$ & $\begin{array}{c}35,1 \\
13,8 \\
\overline{5,8} \\
\overline{0} \\
44,5\end{array}$ & $\begin{array}{l}38,2 \\
1,0 \\
\frac{-0,8}{-} \\
\frac{60,0}{-}\end{array}$ & $\begin{array}{r}45,3 \\
2,3 \\
\frac{1,9}{0,3} \\
\frac{-}{50,1}\end{array}$ & $\begin{array}{r}70,8 \\
15,8 \\
1,2 \\
3,8 \\
1,0 \\
1,3 \\
6,1\end{array}$ & $\begin{array}{r}73,0 \\
14,9 \\
1,1 \\
4,5 \\
0,8 \\
1,1 \\
4,6\end{array}$ & $\begin{array}{r}70,8 \\
14,4 \\
0,7 \\
5,9 \\
0,8 \\
0,5 \\
6,9\end{array}$ \\
\hline $\begin{array}{l}\text { Concentrations totales } \\
\text { mmoles } / \mathrm{kgMS} \ldots \ldots \ldots\end{array}$ & 172,7 & 361,3 & 352,2 & 765,7 & 596,8 & 509,7 \\
\hline
\end{tabular}

(Etienne, 1969).

La production d'acides organiques augmente et se modifie qualitativement avec l'âge de l'animal (Friend, Cunningham et Nicholson, 1963b) ; elle est variable selon la composition du régime (taux de cellulose : Friend, Cunningham et Nicholson, $1963 a$; Argenzio et Southworth, 1975 ; nature ef prétraitements de l'amidon : Ledinek, 1970 ; Koch, Ledinek et Giesecke, 1972 ; présence d'autres types de sucres : Ly, 1974 ; Alvarez et Ly, 1975).

Bien que les concentrations d'acides organiques diminuent vers la fin du gros intestin, on en retrouve encore des proportions importantes dans les fèces chez l'homme (Rubinstein, Howard et Wrong, 1969 ; Newton et al., 1972). Si chez l'Homme, l'élévation du taux de cellulose paraît accroître le taux d'acides organiques dans les fèces (Cummings ef al., 1976), elle modifie sensiblement chez le Porc les proportions des acides gras volatils dans les fèces; l'utilisation de son de blé crée une augmentation de l'acide acétique aux dépens de l'acide propionique, alors que celle de lactosérum augmente la proportion d'acide valérique (Friend, Cunningham et Nicholson, 1962). L'ingestion d'amidon de pomme de terre en place d'amidon de maïs chez le Porc provoque une excrétion accrue d'acides gras volatils, la proportion d'acide butyrique étant significativement accrue (Mason et Just, 1976). Cette excrétion s'accompagne de celle de sucres alimentaires plus ou moins hydrolysés (Delort-Laval et al., 1968). Les laux d'acides gras volatils sont sensiblement diminués dans les fèces lors de traitements par les antibiotiques chez l'Homme (Gompertz ef al., 1973) et chez le Porc (Mason ef Just, 1976). 
1.3. Destinée des produits de dégradation des glucides présents dans le gros intestin.

Ces composés sont des glucides plus ou moins complexes non digérés, des acides gras volatils et de l'acide lactique. Bien entendu, ils peuvent subir un catabolisme plus poussé par la flore et produire du $\mathrm{CO}_{2}$, de l'eau, du $\mathrm{CH}_{4}$ et de l'hydrogène (Levitt ef al., 1974 ; Gumbmann ef Williams, 1971). Mais ces produits peuvent également être absorbés.

1.3.1. Absorption. - Dans le cas des sucres non digérés, on sait que leur absorption, possible dans le côlon et le rectum, y est plus lente que dans l'intestin grêle (Burget et al., 1933 ; Davidson et Garry, 1939). La muqueuse du côlon absorbe le glucose (Heaton, 1972) mais l'instillation rectale du glucose chez l'Homme n'est pas suivie d'un accroissement de la glycémie (Garrer, Groen et Hallen, 1941). Le glucose marqué au ${ }^{14} \mathrm{C}$ introduit dans le côlon est métabolisé et ses produits de dégradation sont absorbés puisque 14 à 25 p. 100 de la dose de carbone 14 est expirée sous forme de $\mathrm{CO}_{2}$, ce phénomène étant supprimé après administration de néomycine ; la radioactivité spécifique du glucose circulant est en outre très faible (Long, Geiger et Kinney, 1967). Il en est de même pour le lactose (Bond et Levitt, 1974).

En ce qui concerne les acides gras volatils, ils sont absorbés chez l'Homme par diffusion non ionique, le taux d'absorption étant lent, d'autant plus que leur chaîne carbonée est plus courte et le pH plus élevé (Dawson, Holdsworth et Webb, 1964 ; Sallee et Dietschy, 1973). L'hypothèse d'un transport actif faite par Barry et Smyth (1960) ne pourrait ainsi être retenue. Chez le Porc, le transport des acides volatils à travers la muqueuse du cæcum et du côlon est plus rapide qu'au niveau de la muqueuse gastrique ; le processus d'absorption est très efficace (Argenzio et Southworth, 1975) et apparemment complet (Farrell et Johnson, 1972). Des acides gras volatils apparaissent dans le sang efférent de l'intestin grêle au cours de la digestion, les concentrations les plus importantes étant atteintes dans la veine cæcocolique (Barcroft, McAnally et Phillipson, 1944). Leurs proportions relatives ont été bien déterminées dans le sang périphérique du porc ( $\mathrm{McClymont,1951)}$ et dans le sang porte (Friend, Nicholson et Cunningham, 1964). Au cours de leur passage dans la muqueuse, des quantités non négligeables en sont utilisées (Ly, 1974 ; Imoto et Namioka, 1978a, b).

Quant à l'acide lactique, il peut également être absorbé dans le gros intestin, mais selon une vitesse moins grande que dans l'intestin grêle ; l'absorption est en relation directe avec la concentration du lactate perfusé et elle n'est pas affectée par un inhibiteur métabolique (Heller et Kern, 1968). Au cours de la digestion de repas à base de lactose ou d'amidon par le Porc (tabl. 4) la lactacidémie est plus élevée dans la veine porte que dans l'artère aorte ; la quantification de l'absorption basée sur les différences porto-artérielles de concentration d'acide lactique et la mesure du débit portal permettent de chiffrer à 20 à $40 \mathrm{~g}$ la quantité d'acide lactique apparaissant dans l'organisme en $8 \mathrm{~h}$ d'absorption (Rérat ef al., 1976, 1978) ; cependant, il faut bien préciser qu'une partie de cet acide lactique provient du travail métabolique de la paroi, tout au long du tractus gastrointestinal (Windmueller et Spaeth, 1978).

1.3.2. Utilisation métabolique. - La quantité d'énergie fournie par la digestion de la cellulose à l'organisme est très discutée (Rérat, 1978). Pour cerfains, la cellulose ne fournit pas d'énergie à l'animal, bien qu'elle soit dégradée. Pour d'autres, des proportions de cellulose allant jusqu'à 50 p. 100 peuvent être dégradées, et les pro- 
TABLEAU 4

Quantités d'acide lactique (moyenne \pm écart-type) apparues dans l'organisme au cours de la digestion Evolution avec le temps

\begin{tabular}{|c|c|c|c|c|c|c|}
\hline & \multirow[t]{2}{*}{$\mathrm{n}$} & \multirow{2}{*}{$\begin{array}{c}\text { Matière } \\
\text { fraî́che }\left(^{*}\right) \\
\text { ingérée }(g)\end{array}$} & \multicolumn{4}{|c|}{$\begin{array}{c}\text { Quantités d'acide lactique }(\mathrm{g}) \text { apparues } \\
\text { dans la veine porte }\end{array}$} \\
\hline & & & $2 \mathrm{~h}$ & $4 \mathrm{~h}$ & $6 h$ & $8 \mathrm{~h}$ \\
\hline $\begin{array}{l}\text { Cerelose } \ldots \ldots \ldots \ldots \\
\text { Saccharose } \ldots \ldots \ldots \\
\text { Amidon de maïs ....... } \\
\text { Lactose } \ldots \ldots \ldots \ldots \\
\text { Amidon d'orge } \ldots \ldots \ldots \\
\text { Amidon de blé........ }\end{array}$ & $\begin{array}{r}13 \\
6 \\
16 \\
8 \\
8 \\
13 \\
11\end{array}$ & $\begin{array}{r}619 \pm 68 \\
542 \pm 93 \\
825 \pm 123 \\
691 \pm 67 \\
731 \pm 129 \\
1011 \pm 129\end{array}$ & $\begin{array}{l}6,7 \pm 1,0 \\
8,8 \pm 1,6 \\
7,1 \pm 0,6 \\
4,3 \pm 0,6 \\
5,1 \pm 0,6 \\
7,4 \pm 0,8\end{array}$ & $\begin{array}{l}14,1 \pm 2,1 \\
14,8 \pm 1,9 \\
14,9 \pm 1,3 \\
10,1 \pm 1,5 \\
10,1 \pm 1,4 \\
14,5 \pm 1,3\end{array}$ & $\begin{array}{l}19,8 \pm 3,0 \\
19,8 \pm 2,3 \\
22,1 \pm 2,0 \\
15,6 \pm 2,4 \\
15,3 \pm 2,2 \\
20,5 \pm 1,8\end{array}$ & $\begin{array}{l}22,6 \pm 3,4 \\
23,4 \pm 3,2 \\
28,3 \pm 2,7 \\
20,0 \pm 3,1 \\
19,0 \pm 2,9 \\
25,8 \pm 2,9\end{array}$ \\
\hline
\end{tabular}

(d'après Rérat et al., 1978). azotées).

$\mathrm{n}=$ nombre de données (repas expérimentaux) $\left({ }^{*}\right)=$ régime entier ( $y$ compris les matières

duits de la digestion absorbés, puisque 50 p. 100 du carbone radioactif de la cellulose marquée apparaît dans le $\mathrm{CO}_{2}$ expiré.

Les produits d'hydrolyse des glucides dans le gros intestin sont plus ou moins bien utilisés au niveau tissulaire. Les acides gras volatils servent certainement de source d'énergie puisqu'il apparaît du ${ }^{14} \mathrm{CO}_{2}$ dans l'air expiré lorsqu'ont été placés des acides gras marqués au ${ }^{14} \mathrm{C}$ dans le cæcum (Yang, Manoharan et Mickelsen, 1970) ou qu'ils ont été ingérés-(McAtee, Little et Mitchell, 1967). Cependant, l'acide acétique, distribué au Rat sous forme de triacétine, présente une valeur nutritive pour la croissance et l'entretien environ 15 p. 100 inférieure à celle de l'amidon (Vermorel, 1968). De même, l'administration au Porc de régimes contenant des pourcentages élevés d'acides gras volatils provoque une dépression de la croissance (Bowland, Young et Milligan, 1971). Par contre, l'acide lactique semble aussi bien utilisé chez le Porc que l'amidon (Charlet-Lery, 1964).

Quoi qu'il en soit, diverses tentatives ont été faites pour apprécier la quantité d'énergie mise à la disposition de l'organisme par l'intermédiaire des fermentations dans le gros intestin. Les données obtenues sont extrêmement variables, et les facteurs de variation sont, semble-t-il, principalement l'espèce ef la nature des glucides présents dans le régime. Sur la base des différences porto-artérielles, on pourrait retenir une absorption de $300 \mathrm{kcal}$ par jour pour les seuls AGV chez un porc de $30 \mathrm{~kg}$. Ces quantités correspondent à peu près aux quantités d'énergie disparues du gros intestin puisque chez un porc de $100 \mathrm{~kg}$ recevant $2 \mathrm{~kg}$ par jour d'un régime à base d'amidon de maïs (soit $7500 \mathrm{kcal}$ ) 560 à $600 \mathrm{kcal}$ disparaissent par jour dans le gros intestin, ce qui correspond à 9 p. 100 de l'énergie digestible ingérée ; mais ces quantités sont doublées lorsque les animaux ingèrent un amidon de pomme de terre (Mason et Just, 1976). Ces données sont du même ordre de grandeur que celles de Holmes, Bayley ef Horney (1973) ef de Imoto et Namioka (1978a). 


\section{Digestion des matières azotées dans le gros intestin et absorption des produits de leur dégradation.}

\subsection{Les matières azotées arrivant dans le gros intestin.}

Les contenus du gros intestin sont formés d'un mélange de résidus provenant de la fraction de l'azote ingéré non résorbée dans l'intestin grêle, mais aussi de produits endogènes (enzymes digestives, mucoprotéines, cellules desquamées, urée, aminoacides produits par le catabolisme cellulaire, serumalbumine, corps microbiens) qui viennent diluer l'azote d'origine exogène.

Au niveau de l'iléon terminal s'accumule la fraction non digérée des protéines alimentaires, en même temps qu'une partie de l'azote endogène. Ce phénomène a bien été mis en évidence chez le Rat par Ochoa Solano et Gitler (1968). Trente minutes après un repas de caséine, une proportion appréciable du repas esł passée dans l'intestin (54 p. 100) et a été absorbée à raison de 85 p. 100, le reste s'accumulant dans l'iléon. La digestion des protéines endogènes s'avère beaucoup plus lente : elles s'accumulent dans l'iléon terminal et ceci se traduit notamment par une élévation de l'activité trypsique à ce niveau. L'importance de l'azote endogène au niveau de l'iléon est fonction de l'alimentation sous deux aspects. D'un côté, les sécrétions digestives sont variables en quantité selon la nature du régime (Zebrowska, 1973a; Buraczewska ef al., 1975). Par ailleurs, la protéolyse des enzymes les moins stables est freinée par la présence de protéines exogènes (Snook et Meyer, 1964).

La contribution de l'azote endogène au flux d'azote et d'acides aminés aux différents niveaux du tube digestif a été particulièrement bien étudiée chez le Porc à l'aide de perfusions d'anses intestinales isolées à divers niveaux du tube digestif (Buraczewska, 1979) ou à l'aide d'une méthode de dilution isotopique après ingestion de protéines marquées au ${ }^{15} \mathrm{~N}$ ou d'ingestion d'acides aminés marqués (Köhler, Zebrowska et Gebhardt, 1978 ; Zebrowska ef al., 1976). Au niveau de l'iléon, l'azote endogène constitue presque entièrement l'azote total, surtout au cours des premières heures après le repas, lorsque les résidus exogènes ne sont pas encore arrivés à ce niveau ; puis entre 4 et 11 h après le repas on assiste à une dilution de cet azote endogène représentant alors 25 p. 100 de l'azote total, suivie d'une reconcentration après $11 \mathrm{~h}(50 \mathrm{p} .100)$. La répartition entre les diverses fractions penche en faveur des résidus solubles (27 p. 100) et de la fraction protéique soluble (30 p. 100) (Köhler, Zebrowska et Gebhardt, 1978). Certains acides aminés s'accumulent préférentiellement à certains niveaux du tube digestif. Au niveau iléal, ce reliquat d'azote endogène vient obérer la digestibilité apparente des acides aminés qui est inférieure (de 3 à 12 points) à la digestibilité réelle (à l'exception toutefois de la lysine, de l'isoleucine et du glycocolle pour lesquels les 2 valeurs sont analogues) (Gebhardt, Köhler et Zebrowska, 1978). Avec un régime protéiprive, les apports iléaux contiennent des quantités élevées de proline, de sérine, glycocolle, thréonine et diacides (Holmes et al., 1974). II faut rappeler que ces acides aminés constituent une large fraction des mucoprotéines (Werner, 1953 ; Bella et Kim, 1972 ; Degand, Gaveriaux et Havez, 1972) et certains d'entre eux (sérine, thréonine) sont très concentrés dans le suc pancréatique (Corring et Jung, 1972).

La quantité d'azote atteignant chez le Porc la jonction iléo-cæcale et les propor- 
tions d'azote exogène qui y sont présentes varient dans de fortes proportions selon la protéine ingérée et la composition du reste du régime. Il en résulte une variabilité extrême de la composition des digesta iléaux. Chez le Porc, la digestibilité apparente de l'azote, dans la partie antérieure du tube digestif peut s'étager entre 60 et 90 p. 100 (cf. Rérat, 1978). D'autres facteurs que la nature de la protéine sont susceptibles d'intervenir tels que le taux de protéines, de lipides ou de cellulose (Just, 1980). En ce qui concerne les acides aminés, leur digestibilité iléale est également très variable (cf. Rérat, 1978 ; Darcy, 1980). Il résulte de cette disparition variable des protéines exogènes au cours de leur transit dans l'intestin grêle que des quantités plus ou moins importantes d'azote avec des proportions différentes d'acides aminés et d'autres principes alimentaires entrent dans le gros intestin et ceci a été montré chez le Porc (Zebrowska, 1973a, b) le Poulet (Payne ef al., 1968) et le Canard (Crompton et Nesheim, 1969).

2.2. Modifications des contenus azotés digestifs au cours du transit dans le gros intestin.

L'utilisation de la technique de canulation permanente de l'iléon a permis d'étudier le rôle de la microflore de façon systématique. A l'exception de certains auteurs (Poppe, Meier ef Bennke, 1977 ; Poppe et Meier, 1977 ; Ivan et Farrell, 1976) l'opinion est maintenant unanime quant à l'importance et la complexité des phénomènes

\section{TABLEAU 5}

Disparition des acides aminés dans l'intestin grêle (I.G.) ef le tube digestif postérieur (G.I.)

Digestibilité des acides aminés chez des porcs recevant des régimes semi-purifiés avec du tourteau de soja comme unique source protéique

\begin{tabular}{|c|c|c|c|c|c|c|}
\hline \multirow{2}{*}{ Acides aminés } & \multicolumn{3}{|c|}{ Holmes ef al. (1974) } & \multicolumn{3}{|c|}{$\begin{array}{c}\text { Zebrowska et Burac- } \\
\text { zewski (1977) }\end{array}$} \\
\hline & I.G. & G.I. & Total & I.G. & G.I. & Total \\
\hline \multicolumn{7}{|l|}{ Essentiels : } \\
\hline 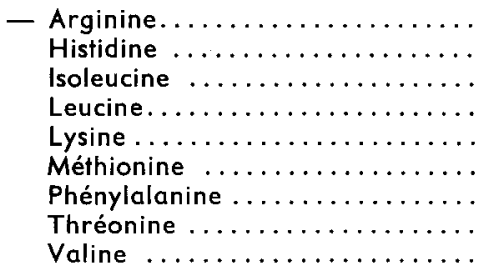 & $\begin{array}{l}93,5 \\
97,0 \\
86,5 \\
87,0 \\
90,7 \\
96,7 \\
87,9 \\
82,2 \\
84,6\end{array}$ & $\begin{array}{l}- \\
\overline{33,3} \\
16,1 \\
12,5 \\
\overline{22,9} \\
11,7 \\
36,8\end{array}$ & $\begin{array}{l}86,9 \\
96,4 \\
91,0 \\
89,1 \\
91,9 \\
79,1 \\
90,8 \\
84,3 \\
90,3\end{array}$ & $\begin{array}{l}87,4 \\
80,3 \\
80,3 \\
80,5 \\
80,9 \\
82,0 \\
80,9 \\
69,6 \\
76,2\end{array}$ & $\begin{array}{l}47 \\
58 \\
31 \\
38 \\
43 \\
12 \\
45 \\
57 \\
41\end{array}$ & $\begin{array}{l}93,3 \\
91,6 \\
86,4 \\
88,0 \\
89,1 \\
84,2 \\
89,4 \\
86,8 \\
86,0\end{array}$ \\
\hline \multicolumn{7}{|l|}{ _- Non essentiels : } \\
\hline 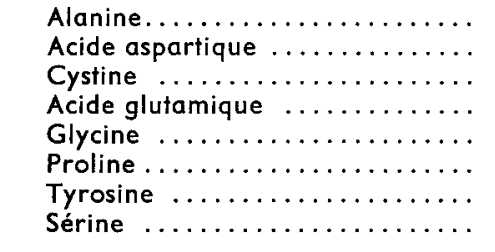 & $\begin{array}{l}81,1 \\
87,0 \\
92,3 \\
89,7 \\
71,6 \\
71,8 \\
88,6 \\
86,3\end{array}$ & $\begin{array}{c}10,9 \\
19,5 \\
- \\
29,5 \\
52,8 \\
90,8 \\
- \\
12,5\end{array}$ & $\begin{array}{l}83,1 \\
89,5 \\
73,1 \\
92,7 \\
86,5 \\
97,4 \\
86,9 \\
87,8\end{array}$ & $\begin{array}{l}74,9 \\
77,7 \\
66,4 \\
82,1 \\
64,7 \\
93,5 \\
72,9 \\
75,9\end{array}$ & $\begin{array}{l}42 \\
56 \\
67 \\
62 \\
58 \\
67 \\
43 \\
59\end{array}$ & $\begin{array}{l}85,4 \\
90,2 \\
89,0 \\
93,3 \\
85,0 \\
91,3 \\
84,6 \\
90,1\end{array}$ \\
\hline Total $\ldots \ldots \ldots \ldots \ldots \ldots \ldots$ & 86,5 & 23,1 & 89,6 & 72,4 & 58 & 87,7 \\
\hline
\end{tabular}


touchanf la digestion des matières azotées dans le gros intestin. Ces phénomènes conduisent à la fois à la disparition d'azote et de certains acides aminés entre l'iléon ef le rectum mais également à l'apparition de certaines substances durant le passage cæcocolique des digesta. Ces phénomènes, mis en évidence chez la Volaille (Salter et Coates, 1971), ont été largement confirmés chez le Porc.

Chez cette dernière espèce la disparition dans le gros intestin des matières azotées présentes dans l'iléon s'étend de 15 à 50 p. 100 (cf. revue de Rérat, 1978). Il s'agit toutefois en l'occurrence de quantités journalières d'azote faibles, ce qui explique les variations des proportions enregistrées. En outre, la digestibilité dans le gros intestin varie selon l'acide aminé considéré et la protéine ingérée. En général, les acides aminés de faible digestibilité dans l'iléum sont dégradés dans de grandes proportions dans le gros intestin (łabl. 5). Pour certains autres acides aminés, les quantités présentes dans les fèces sont plus élevées que celles passant dans l'iléon (Low, 1979 ; Holmes et al., 1974 ; Mason, Just ef Bech-Andersen, 1976). Des moyennes établies à partir de 37 régimes (Just, 1980), il ressort que la méthionine est l'acide aminé le plus souvent concerné par cette apparition (tabl. 6).

\section{TABLEAU 6}

Déviations moyennes de la digestibilité apparente de l'azote et des acides aminés ef disparition dans le gros infestin (p. 100 de l'ingéré)

\begin{tabular}{|c|c|c|c|}
\hline \multirow{2}{*}{$\begin{array}{c}\text { Digestibilité apparente } \\
\text { de l'azote }\end{array}$} & \multicolumn{2}{|c|}{$\begin{array}{l}\text { Déviation de la digestibilité } \\
\text { apparente de l'azote au niveau de : }\end{array}$} & \multirow{2}{*}{$\begin{array}{l}\text { Disparition dans } \\
\text { le gros intestin } \\
8\end{array}$} \\
\hline & Iléum ferminal & Rectum & \\
\hline 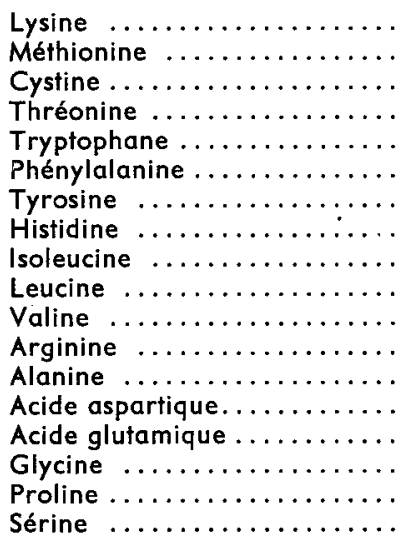 & $\begin{array}{r}6 \\
9 \\
-5 \\
-3 \\
0 \\
8 \\
6 \\
9 \\
6 \\
7 \\
4 \\
9 \\
-1 \\
1 \\
12 \\
-9 \\
3 \\
3\end{array}$ & $\begin{array}{r}0 \\
0 \\
0 \\
-1 \\
3 \\
4 \\
2 \\
7 \\
1 \\
3 \\
2 \\
7 \\
-3 \\
1 \\
9 \\
0 \\
7 \\
4\end{array}$ & $\begin{array}{r}2 \\
-1 \\
13 \\
10 \\
11 \\
4 \\
4 \\
6 \\
3 \\
4 \\
6 \\
6 \\
6 \\
8 \\
4 \\
17 \\
12 \\
9\end{array}$ \\
\hline Somme des acides aminés .... & 4 & 3 & 7 \\
\hline
\end{tabular}

(d'après Just, 1980).

A noter que chez le poulet axénique, les acides aminés dont la digestibilité iléale est peu élevée s'accumulent dans le gros intestin (Salter et Fulford, 1974) ce qui témoigne à nouveau du rôle de la microflore dans ces phénomènes. 
II ressort de l'ensemble des expériences rapportées que de grandes différences subsistent d'un auteur à l'autre. Lors de l'emploi de régimes protếiprives certains auteurs (Holmes et al., 1974) enregistrent une fixation journalière d'azote dans les contenus du gros intestin, alors que d'autres (Zebrowska et Buraczewski, 1977) y constatent la disparition d'une fraction importante des acides aminés présents dans les contenus iléaux. Ces différences sont probablement dues en partie à l'état antérieur de nutrition azotée de l'animal. En effet, on sait qu'une proportion non négligeable de l'urée synthétisée dans l'organisme diffuse dans l'intestin grêle ef sert éventuellement de substrat à des synthèses bactériennes dans le gros intestin. Or l'urémie est variable selon les « réserves » azotées de l'animal, et les synthèses peuvent être de ce fait variables selon, par exemple, la durée de la période d'administration du régime protéiprive. Dans le cas d'administration de régimes azotés, ces différences peuvent être attribuées à la nature de l'aliment protidique. Cependant, ces différences subsistent même quand sont utilisés des aliments de même composition (régime à base de soja). Elles sont donc dues à d'autres causes parmi lesquelles la nature des substrats énergétiques du régime revêt une importance notable.

\subsection{Modifications de l'évolution chimique des contenus du gros intestin en fonction du régime.}

On sait depuis longtemps que la perte fécale d'azote dépend prticipalement des caractéristiques des protéines alimentaires. Selon Dammers (1964) et Eggum (1973), la digestibilité vraie de chacun des acides aminés d'une protéine donnée serait ainsi intangible chez le Porc et le Rat. A l'encontre de ces observations, d'autres expériences (cf. Rérat, 1978) ont prouvé l'influence sur la perte fécale azotée de la teneur en azote et du traitement des matières azotées, du taux de cellulose, de l'amidon et de son prétraitement et des sucres du régime. On peut évidemment se demander si ces changements de la perte fécale sont liés à une variation de la digestibilité vraie de la protéine par protection des digesta vis-à-vis des attaques enzymatiques (Bergner, Simon et Zimmer, 1975) ou au contraire à une modification de l'importance de la perte fécale d'origine métabolique, constituée en majeure partie par les microorganismes (McNeal, Latzer ef Kerr, 1909 ; Smith, 1961 ; Mason, 1969). Chez le Rat, l'influence de la nature ef du taux d'introduction des constituants glucidiques du régime sur l'excrétion des microorganismes a été systématiquement étudiée, de même que l'influence de la protéine ingérée (Mason et Palmer, 1973). Il ressort de ces travaux qu'une fraction importante de l'azote fécal est présente dans les déchets bactériens, et ceci d'autant plus que les protéines sont plus digestibles ; en outre, la quantité d'azote fécal total et d'azote fécal d'origine bactérienne peut être influencée par la nature des glucides présents dans le régime, sans doute en fonction du volume des résidus de sucres non digérés entrant dans le caecum ef de leur action sur l'activité microbienne dans le gros intestin. Cependant, ce mécanisme n'est pas le seul en cause comme le montrent les travaux sur la cellulose : Bergner, Simon ef Zimmer (1975) font état de l'adsorption d'acides aminés et de peptides sur la cellulose, ainsi que d'un accroissement de la desquamation intestinale, d'où résulte une excrétion accrue d'azote. La nature de la cellulose serait la cause de la divergence de son action sur la digestibilité de l'azote (Eggum, 1973 ; Breite ef al., 1973 ; Saver, 1976). 
Chez le Porc, il est également bien montré que la nature de la fraction énergètique de l'aliment (cellulose : Just, 1980 ; origine botanique de l'amidon ; Mason, Just et Bech-Andersen, 1976 ; traitement technologique : Livingstone et al., 1977) a une influence marquée sur l'importance des phénomènes d'apparition ou de disparition des matériaux azotés dans le gros intestin. La taille des particules alimentaires peut également avoir son importance (Saver, 1976) (tabl. 7). Chez le Porc, le blé finement broyé présente une digestibilité iléale de l'azote, de la matière sèche et des acides aminés plus élevée que le blé grossièrement broyé. La disparition d'aminoacides dans le gros intestin est plus élevée pour le blé grossièrement broyé que pour le blé finement broyé. Ce fait est probablement lié à l'arrivée à ce niveau de quantités plus importantes d'amidon non digéré, ce qui provoquerait un accroissement des fermentations microbiennes. En définitive, les digestibilités fécales des acides aminés diffèrent très peu entre les deux traitements alors que la nature des éléments absorbés a été différente. Dans le cas du blé finement broyé, il s'est agi en fait d'acides aminés provenant de l'at iorption dans l'intestin grêle, alors que dans le cas du blé grossièrement broyé, une partie de ces acides aminés a dû subir une dégradation bactérienne préalable, ce qui altère probablement la valeur nutritionnelle du produit absorbé.

\section{TABLEAU 7}

Différences (en p. 100) (A) entre les digestibilités apparentes focales ef iléales des acides aminés du blé finement ou grossièrement broyé et disparition pourcentuelle (B) de ces derniers dans le gros intestin

\begin{tabular}{|c|c|c|c|c|}
\hline \multirow[b]{3}{*}{ Acides aminés } & \multicolumn{4}{|c|}{ Particules alimentaires } \\
\hline & \multicolumn{2}{|c|}{ Fines } & \multicolumn{2}{|c|}{ Grossières } \\
\hline & A & B & A & B \\
\hline 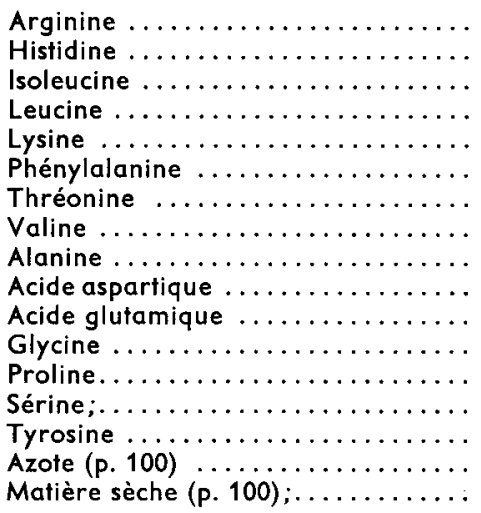 & $\begin{array}{r}2,2 \\
3,3 \\
1,0 \\
1,4 \\
3,8 \\
0,6 \\
5,0 \\
2,7 \\
5,0 \\
4,3 \\
2,5 \\
8,4 \\
11,4 \\
5,1 \\
0,9 \\
5,0 \\
8,4\end{array}$ & $\begin{array}{r}30,0 \\
37,1 \\
10,2 \\
16,5 \\
20,5 \\
8,5 \\
30,7 \\
23,7 \\
27,9 \\
25,0 \\
53,2 \\
45,9 \\
73,5 \\
43,2 \\
8,8 \\
51,7 \\
42,9\end{array}$ & $\begin{array}{r}7,4 \\
8,2 \\
4,3 \\
4,5 \\
11,2 \\
3,5 \\
9,3 \\
7,4 \\
12,0 \\
8,9 \\
3,5 \\
15,4 \\
12,5 \\
5,6 \\
5,3 \\
7,6 \\
12,0\end{array}$ & $\begin{array}{l}54,8 \\
57,3 \\
29,9 \\
36,3 \\
40,9 \\
33,0 \\
42,3 \\
43,8 \\
47,1 \\
39,2 \\
59,3 \\
60,2 \\
77,2 \\
36,6 \\
36,1 \\
49,7 \\
51,7\end{array}$ \\
\hline
\end{tabular}

(Sauer, 1976).

Ces expériences montrent que la perte fécale d'azote en quantité et en qualité est non seulement fonction de la nature des matières azotées et de leur prétraitement, mais est aussi en relation étroite avec la nature des sucres du régime, en raison de l'activité plus ou moins stimulée de la flore microbienne du tube digestif postérieur et d'une fixation plus ou moins importante d'azote dans les bactéries. 
2.4. Modifications de la composition des fèces ou des contenus cæcocoliques à la suite de cæcectomie ou de suppression partielle ou complète de la flore bactérienne.

Le rôle du tube digestif postérieur dans la digestion de l'azote a également été étudié à l'aide de résection du cæcum (Payne et al., 1968 ; Dreyer, Concamon et de Klerk, 1975), ou encore par une modification de la flore à l'aide de substances antibiotiques ou par comparaison entre animaux holoxéniques ou axéniques.

2.4.1. Influence des antibactériens ef des antibiotiques sur la digestion ef l'absorption dans le gros intestin. - Des premières recherches réalisées in vivo sur le Rat (Kuiken, 1952 ; Kuiken et Lyman, 1948 ; Harper ef de Muelenaere, 1963) ou le Porc (Dammers, 1964), il ressortait que la digestibilité globale des acides aminés n'était pas modifiée par l'addition de succinylsulfathiazole (2 à 5 p. 100) dans le régime. Ces résultats étaient ensulte confirmés chez le Rat par Eggum (1973) à. l'aide de sulfathiazole (2 p. 100) ou de chlortétracycline à dose nutritionnelle $(20 \mathrm{ppm})$. Cependant certaines études avaient, entre temps, montré que l'excrétion de l'azote fécal métabolique était diminuée lors de l'emploi des antibiotiques à faible dose (Rérat, Poullain et Jacquot, $1958 \mathrm{chez}$ le Rat ; Delort-Laval, Charlet-Lery et Zelter, 1963 chez le Porc). Plus récemment, des résultats compilés par Just (1980), il ressort que l'addition d'antibiotiques à faible dose au régime du Porc peut augmenter la digestibilité apparente de certains acides aminés de 3 à 5 points ; la proportion d'azote d'origine microbienne dans l'azote fécal est diminuée significativement par l'emploi de nébacitine (Mason, Just et Bech-Andersen, 1976). En tout état de cause, qu'il s'agisse de sulfamides utilisés à doses élevées, ou d'antibiotiques à faible dose, il faut préciser que la flore digestive n'est pas totalement inhibée et qu'il s'y produit, outre une diminution du nombre des microorganismes, une modification de l'équilibre des espèces microbiennes en présence.

Il faut ajouter que, à faible dose, la chlortétracycline (Larson et Hill, 1960), l'oxyttréacycline et l'acrylate de sodium (Michel ef al., 1964) inhibent la formation d'amines dans l'intestin du jeune porc; ces amines sont produites par les décarboxylases bactériennes, particulièrement celles d'E. Coli, dont la population spécifique est moins nombreuse chez les animaux soumis aux antibiotiques. La chlortétracycline inhibe in vitro le métabolisme de la flore, spécialement le catabolisme des matières azotées et des sucres (Michel, 1961a, b).

2.4.2. Influence de la vie axénique sur la digestion ef l'absorption dans le gros intestin. - L'influence de la flore sur la digestion ef l'absorption dans le gros intestin a également été montrée par comparaison des contenus intestinaux d'animaux axéniques ou holoxéniques. Ces comparaisons ont porté sur la composition des contenus cæcaux ou des fèces.

2.4.3. Analyse des contenus cæcaux. - On sait depuis longtemps que le cæcum est plus volumineux dans les conditions de vie axénique (Nuttal et Thierfelder, 1896) ; ce phénomène n'est toutefois perceptible que chez les rongeurs (Wostmann et Bruckner-Kardoss, 1959). Quel que soit le taux azoté du régime, le cæcum d'animaux axéniques contient 2 à 4 fois plus d'azote que celui des holoxéniques (Combe ef Pion, 1966 ; Combe et al., 1965). La caractéristique principale de ces matières azotées est qu'elles sont en majeure partie sous forme soluble chez le rat axénique à l'inverse de ce qui se passe chez l'holoxénique (Combe et al., 1965 ; Loesche, 1968a, b) ce fait étant 
également vrai chez la volaille (Coates, Hewitt et Golob, 1970). Une analyse plus poussée de ces contenus (Combe et Pion, 1966 ; Combe et al., 1970) permet d'y déceler trois fractions selon leur degré de solubilité dans l'éthanol ou dans l'acide trichloracétique. Chacune de ces fractions est modifiée par la présence ou l'absence de flore, les fractions solubles variant respectivement entre 62 et 69 p. 100 , et 15 à 24 p. 100 du total chez les axéniques.

On trouve, dans la fraction éthano-soluble, de l'urée, de l'acide urique, des hexosamines, et des acides aminés en quantités plus importantes chez l'axénique que chez l'holoxénique (Yoshida, Pleasants et Wostmann, 1972 ; Salter et Coates, 1970, 1971). Cette fraction éthanolique contient pratiquement tous les acides aminés libres en concentration (dans les contenus frais) dix fois supérieure à celle trouvée chez les holoxéniques; la répartition de ces acides aminés libres n'est du reste pas la même pour les deux types d'animaux (Combe et al., 1965 ; Combe et Sacquet, 1966). A l'inverse des axéniques, cette fraction éthanolique des contenus des holoxéniques ne contient d'urée qu'en concentration très inférieure au plasma sanguin mais dix fois plus d'ammoniaque ce qui a également été montré chez la volaille (Salter, Coates et Westgarth, 1971). Toutefois, l'ammoniaque, l'urée et les acides aminés libres ne rendent compte que de 13 à 26p. 100 de l'azote présent dans cette fraction (Combe et al., 1965 ; Combe et Sacquet, 1966), qui contient également des chaînes peptidiques courtes renfermant 3 à 4 résidus d'acides aminés et une partie des hexosamines des contenus cæcaux sous forme de mucoprotéines.

La fraction acido-soluble des contenus cæcaux d'animaux axéniques est composée essentiellement de mucoprotéines (Combe et Pion, 1966) et de peptides à chaîne plus longue ( 6 à 9 résidus). La composition en aminoacides de cette fraction se rapproche de celle des glycoprotéines (Alais ef Jolles, 1964). En présence de la flore, outre la diminution de l'imporiance quantitative de cette fraction, on observe la disparition de la thréonine, de la tyrosine, et de la méthionine, acides aminés caractéristiques des mucoprotéines (Werner, 1953). L'importance des mucoprotéines chez les axéniques et leur dégradation dans le cæcum des animaux holoxéniques a également été mise en évidence par Lindstedt, Lindsłedt et Gustafsson (1965).

Quant à la fraction azotée insoluble dont l'importance pondérale est réduite chez le rat axénique, sa composition chez cet animal est très voisine de celle de la paroi intestinale : l'action de la flore se traduit par une diminution importante de la teneur en protéines, et une augmentation importante de la teneur en lysine peut être liée à la présence de corps microbiens. L'action de la flore se traduit également par l'inactivation des enzymes protéolytiques pancréatiques (Borgström et al., 1959 ; Loesche, 1968a, b) dont l'activité rémanente est relativement importante à ce niveau chez l'axénique (Loesche, 1968a, b).

En définitive, il apparaît que s'accumulent au niveau du cæcum des animaux axéniques, divers composés endogènes : mucoprotéines, enzymes, cellules desquamées, peptides à chaîne plus ou moins longue, acides aminés libres. La flore microbienne aurait ainsi un rôle important dans la dégradation de ces protéines d'origine endogène.

- Composition des fèces : L'influence de la vie axénique sur la digestibilité de l'azote ou des acides aminés a fait l'objet de nombreuses discussions (cf. Rérat, 1978). Pour certains, l'excrétion fécale serait diminuée; pour d'autres, elle serait augmentée. 
Ces désaccords sont liés probablement aux conditions expérimentales différentes, notamment la nature et le taux de matières azotées ingérées, mais également la fraction glucidique du régime. Les expériences récentes réalisées sur le Rat et l'Agneau sont susceptibles de fournir quelques explications à ces différences (Pion ef al., 1977).

Ainsi l'action de la microflore serait très différente selon la digestibilité des matières azotées alimentaires : elle peuł diminuer la digestibilité apparente de l'azołe lorsque l'excrétion d'azote exogène dans les fèces est faible ef peut accroître la digestibilité lorsque les apports d'acides aminés non digérés dans l'intestin grêle sont élevés.

Chez le Poulet (Salter et Fulford, 1974), la vie axénique ne modifie pas la digestibilité apparente ou vraie de chacun des acides aminés alimentaires (à l'exception foutefois de la thréonine dont la digestibilité vraie est améliorée). La microflore a peu d'aptitude à dégrader les protéines surchauffées (Salter et Fulford, 1974 ; Erbersdobler et Riedel, 1972) mais jove un rôle important dans la dégradation des protéines endogènes (Salter, Coates ef Hewitt, 1974). Elle intervient de ce fait dans la conservation et le recyclage de l' $N$ endogène dans la mesure où cet azote est absorbé ; il esł par ailleurs douteux que les synthèses microbiennes d'acides aminés essentiels enregistrées puissent être valorisées par l'animal en l'absence de coprophagie (Salter et Fulford, 1974).

\subsection{Destinée des produits de la digestion dans le gros intestin.}

Les matières azotées présentes dans le gros intestin peuvent subir diverses destinées selon leur taille et le temps de transit dans cet organe : absorption en nature, dégradation suivie de l'absorption des produits formés ou de l'incorporation des produits formés dans les bactéries, excrétion en nature ou sous forme de bactéries, excrétion suivie ou non de coprophagie.

\subsubsection{Absorption en nature.}

La possibilité de l'absorption en nature de protéines intactes a été mise en évidence dans des anses isolées de côlon de rat à l'aide de péroxydase de raifort (Worthington et Enwonwu, 1975). Ce mécanisme pourrait expliquer la pénétration de la barrière muqueuse par des antigènes et des toxines.

Par ailleurs, chez le Porc nouveau-né, le côlon proximal est capable de transporter activement la méthionine (James et Smith, 1976 ; Smith ef James, 1976). Par contre, il n'a pas été possible de faire la preuve d'un transport actif d'aminoacides ou de glucides simples par la paroi du côlon chez des mammifères plus âgés (Cordero et Wilson, 1961 ; Parsons ef Paterson, 1965) ou chez la volaille (Isshiki ef al., 1974). L'absence de transport actif d'aminoacides par le côlon n'élimine pas la possibilité d'absorption par cet organe mise en évidence chez d'autres espèces (Demaux ef al., 1961). De fait, l'alanine peut entrer dans la muqueuse du côlon, mais non contre un gradient de concentration (Binder, 1970) ; il s'agit là probablement d'un mécanisme indépendant de l'énergie, comme l'est la diffusion. Il faut donc retenir cefte possibilité (Niiyama ef al., 1978). Mais en l'absence de toute donnée quantitative, il est impossible de préciser si un tel mécanisme peut jouer un rôle nutritionnel.

\subsubsection{Catabolisation des matières azotées.}

2.5.2.1. Activité catabolique de la flore cæcale. - En l'absence d'activité protéo- 
lytique dans la paroi du cæcum (Isshiki et al., 1974), les matières azotées présentes dans le gros intestin sont susceptibles d'être dégradées par la flore. Ainsi Michel (1966) a pu montrer in vitro que la flore cæcale de Porc était capable de dégrader tous les acides aminés par décarboxylation ef désamination (†abl. 8).

\section{TABLEAU 8}

Dégradation des acides aminés par la flore du cæcum du porc $\left({ }^{a}\right),\left({ }^{b}\right)$

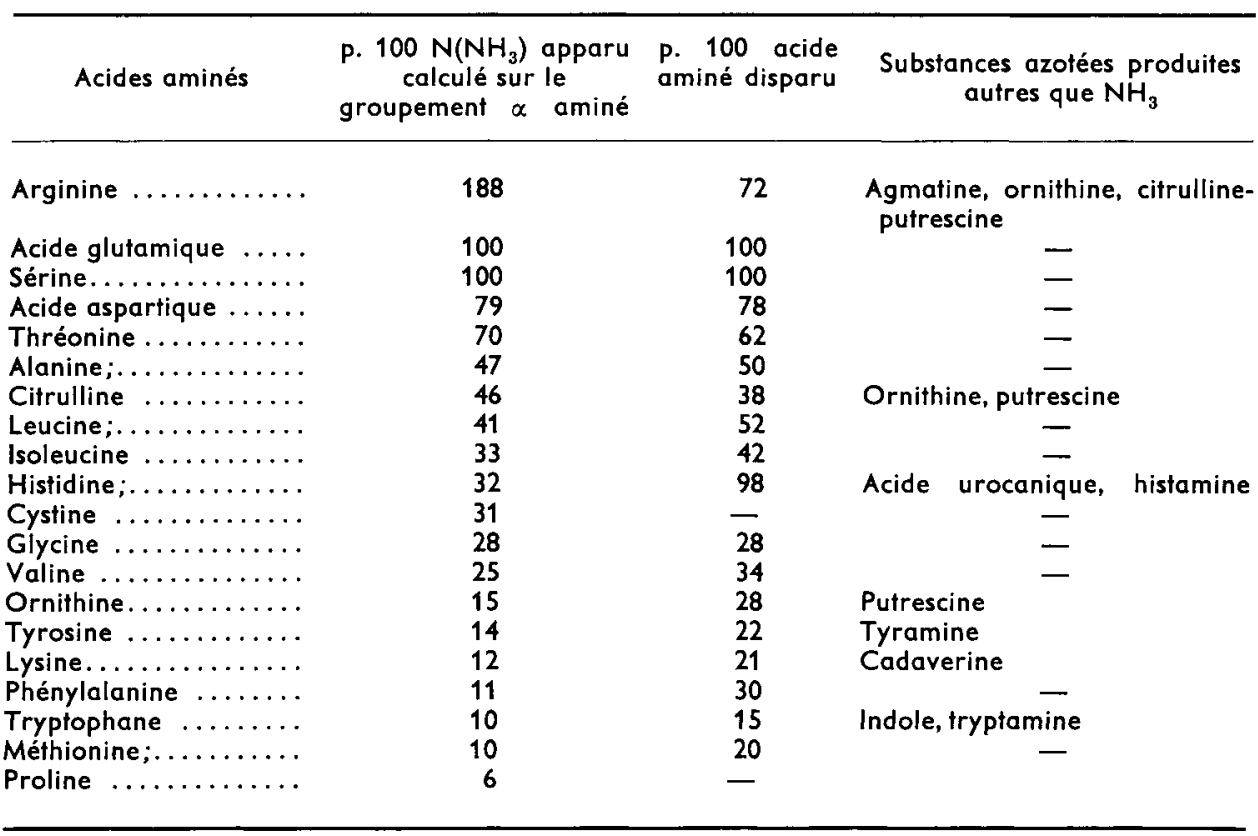

(a) Michel (1966). ( $\left.{ }^{b}\right)$ Substrat $M / 50$; flore au $1 / 4 ; 16$ h d'incubation. Essais sur 80 animaux abattus en hiver.

Les produits fournis vont des plus petites molécules $\left(\mathrm{NH}_{3}, \mathrm{CO}_{2}\right)$ à des corps plus complexes comme les amines. Ces substances sont du reste trouvées normalement in vivo dans le tube digestif du Porc (Michel ef al., 1964) et la formation d'indole a pu être montrée dans le tube digestif postérieur du Rat (Whitt et Demoss, 1975). La dégradation ne s'adresse pas uniquement à des composés normalement présents dans les protéines tels que les acides aminés, mais également à des composés tels que ceux créés par les traitements thermiques au cours des premières étapes de la réaction de Maillard entre sucres et acides aminés (Erbersdobler, 1971, 1973).

Si la dégradation par la flore est manifeste, le modèle in vitro ne permet pas de conclure que, dans le tube digestif, elle est aussi poussée qu'en incubateur, ni de présumer de la destinée ultérieure des corps formés. Quelques indications sont dès lors fournies par les études in vivo concernant aussi bien les composés d'origine alimentaire (protéines, peptides, acides aminés) que ceux d'origine endogène (enzymes, mucoprotéines, microorganismes, urée).

2.5.2.2. Digestion des composés d'origine alimentaire. - La preuve directe de la 
métabolisation des matières azotées alimentaires dans l'intestin postérieur a pu être fournie à l'aide de protéines marquées chez la Volaille (Salter et Coates, 1971) : après administration de blanc d'œuf marqué au ${ }^{14} \mathrm{C}$, et lyophilisé ou détérioré par la chaleur, on constate au niveau de l'intestin postérieur, une disparition plus forte de l'azote que du ${ }^{14} \mathrm{C}$, cetfe différence étant atténuée lorsque la protéine est détériorée par la chaleur. Ce fait est interprété comme lié à une protéolyse bactérienne suivie d'une désamination avec absorption ultérieure de l'ammoniaque. Ce composé est du reste trouvé en quantité 4 à 5 fois plus importante dans le cæcum des animaux holoxéniques que dans ceilui des axéniques. Sa destination est d'être absorbé puisque sa concentration dans le sang porte est beaucoup moins élevée chez les animaux axéniques (cobaye : Warren et Newton, 1959) ou recevant des antibiotiques (Porc : François et Michel, 1958) que chez les animaux holoxéniques.

A côté de la désamination des protéines alimentaires, peuvent exister des cas où l'action de la flore permet une valorisation nutritionnelle d'acides aminés ingérés sous une forme inutilisable. Ainsi, le Rat recevant dans son régime la DL-acétylméthionine, peut utiliser la fraction méthionine de ce composé, soit après absorption directe, soit après coprophagie (Erbersdobler, Gropp et Scharrer, 1972) ; il n'est cependant pas sûr que cette dégradation suivie d'absorption se fasse dans le gros intestin.

Enfin, il faut rappeler que la diminution de digestibilité des protéines est souvent associée à une augmentation de l'excrétion des microorganismes et de l'azote endogène (Mason ef Palmer, 1973 ; Mendes Pereira, Pion et Prugnaud, 1977).

Il semble ainsi que la métabolisation d'une fraction non négligeable des matières azotées alimentaires dans le gros intestin corresponde d'une part à une désamination et à une absorption d'une fraction de l'ammoniaque fournie, d'autre part à l'incorporation de l'azote dans les microorganismes.

En tout état de cause, il apparaît que les substances azotées d'origine alimentaire arrivant dans le cæcum, même si elles y disparaissent, sont mal utilisées par l'organisme à des fins métaboliques, chez le Poulet (Salter, Coates ef Hewitt, 1974) comme chez le Porc (Zebrowska, 1973c, 1975). Si, par une canule, on introduit dans l'iléon terminal du Porc une caséine, non traitée ou endommagée par la chaleur (Zebrowska, Buraczewska et Horaczynski, 1977), on constate une disparition marquée de l'azote dans le gros intestin de telle sorte que l'excrétion fécale est à peine plus élevée que lors de l'ingestion orale dans le cas de la caséine non traitée, mais sensiblement plus forte dans le cas de la caséine traitée. L'azote absorbé n'est cependant pas complètement rejeté dans l'urine puisque le coefficient de rétention de l'azote tombe seulement de moitié. La diminution de l'activité de la flore par les antibiotiques ne modifie pas l'utilisation métabolique de l'azote dans le cas de la caséine non traitée, mais la diminue fortement dans le cas de la caséine traitée.

A noter cependant que s'il y a formation d'ammoniaque au niveau du gros infestin, une partie peut en être utilisée pour la synthèse tissulaire. L'introduction de sels d'ammonium et d'urée marqués au ${ }^{15} \mathrm{~N}$ dans des régimes paurres en azole a permis de montrer l'incorporation de l'isotope dans divers acides aminés tissulaires, et dans divers tissus chez le Rat (Foster, Rittenberg et Schoenheimer, 1938 ; Rittenberg. Schoenheimer et Keston, 1939 ; Rose ef Dekker, 1956), chez l'Enfant (Snyderman et al., 1962) et chez le Porc (Liv et al., 1955 ; Grimson, Bowland et Milligan, 1971 ; 
Niiyama ef al., 1978) ; cette incorporation ne paraît possible que dans la mesure où l'urée peut être dégradée en ammoniaque par les microorganismes du tube digestif (Deguchi et al., 1978). En tout état de cause, l'urée (Rérat et Bourdon, 1972, 1974) ef surtout le citrate d'ammonium (Kagota et al., 1979) sont susceptibles de remplacer une fraction des acides aminés non essentiels pour la croissance du Porc.

\subsubsection{Digestion des matières azotées d'origine endogène.}

- Enzymes : Le fait qu'elles soient normalement dégradées dans le gros intestin ressort des comparaisons entre animaux axéniques ef holoxéniques ; d'après Genell, Gustafsson et Ohlsson (1976), chez le rat holoxénique, l'activité trypsique est la plus élevée dans l'iléon distal, et disparaît brusquement dans le cæcum. La trypsine, absente des fèces de rats holoxéniques, est présente dans celles des rats axéniques. La microflore du cæcum joverait ainsi un rôle dans l'inactivation des enzymes pancréatiques, ce qui avait du reste été déjà antérieurement démontré par Borgström ef al. (1959) et Lindstedt ef al. (1965). L'emploi d'antibiotiques chez le Rat a permis d'aboutir à la même conclusion (Barnes et Kwong, 1965).

- Mucoprotéines : La preuve de leur dégradation par la flore est fournie par l'accumulation de certains de leurs acides aminés constitutifs (sérine, proline, glycine, thréonine, les diacides) dans le gros intestin des animaux axéniques (cf. paragraphe 2.4.2) ; elle est également fournie par la digestibilité iléo-rectale très élevée de ces acides aminés chez l'holoxénique.

- Corps microbiens : La question est de savoir si, dans le gros intestin, les microorganismes peuvent s'autolyser, et si, dans ces conditions, les protéines bactériennes libérées ne sont pas utilisées par les bactéries vivantes pour leur propre croissance. II est bien difficile de trancher. Il faut cependant noter que, selon Yang et al. (1972), à partir de cultures d'E. coli marqué au ${ }^{14} \mathrm{C}$, placées dans le cæcum de rats, une partie non négligeable $(30$ p. 100$)$ de la dose radioactive est retrouvée dans les tissus des animaux, et une fraction ( $5 \mathrm{p} .100)$ est expirée sous forme de $\mathrm{CO}_{2}$; les bactéries peuvent donc être digérées en partie dans le cæcum et les produits de leur digestion absorbés à ce niveau et utilisés au niveau métabolique. Des travaux japonais récents chez le Porc (Niiyama et al., 1978) permettent de penser que les microorganismes du gros intestin sont capables non seulement de synthétiser leurs protéines microbiennes à partir d'urée ${ }^{15} \mathrm{~N}$, mais de diffuser des acides aminés sous forme libre hors de cellules microbiennes, l'absorption de ceux-ci étant possible par la veine iléocolique. II faudrait bien entendu pouvoir quantifier ce phénomène pour connaître son importance.

- Urée : On a déjà souligné que les contenus du gros intestin des animaux axéniques renfermant des concentrations d'urée analogues à celles présentes dans le sang (cf. paragraphe 2.4.2) alors qu'il n'y en a pas chez les animaux holoxéniques ; à l'inverse, on trouve chez ces derniers des quantités notables d'ammoniaque, mais non chez les axéniques. On peut ainsi penser que la microflore provoque la dégradation de l'urée en libérant ammoniaque et gaz carbonique. Ce fait est confirmé par la suppression du catabolisme de l'urée lors de l'ablation totale du tractus gastrointestinal chez l'animal (Chao et Tarver, 1953). Chez l'Homme, l'hydrolyse de l'urée par l'uréase bactérienne mise en évidence dans la lumière du côlon est inhibée par l'addition d'antibiotiques (Evans, Aoyagi et Summerskill, 1966 ; Wilson et al., 1968 ; Wrong et al., 1970). 
Par ailleurs, il existe très peu d'activité uréasique dans la muqueuse du côlon de l'Homme (Aoyagi et al., 1966). L'hydrolyse de l'urée se produit dans une situation juxta mucosàle puisque l'urée administrée par voie intraveineuse est métabolisée plus rapidement que celle introduite par infusion dans l'organe (Wolpert, Phillips et Summerskill, 1971). Ce sont les anaérobies non sporulés qui sont la source la plus importante d'uréase (Brown, Hill ef Richards, 1971) et leur proportion augmente quand augmente le taux d'urée sanguine.

D'où vient l'urée métabolisée dans le tube digestif? Elle provient d'une part des sécrétions digestives : salive (Simonnet, Le Bars et Mollé, 1957), suc gastrique (Fillastre et al., 1965), bile (Wrong ef al., 1970) notamment. Elle diffuse également librement depuis le sang dans les divers organes : estomac (Fleshler et Gabuzda, 1965) et intestin grêle de l'Homme (Ewe et Summerskill, 1965) mais le côlon lui est relativement imperméable (Billich et Levitan, 1969 ; Summerskill et Wolpert, 1970 ; Wolpert, Phillips et Summerskill, 1971). En fait, l'intestin grêle est beaucoup plus perméable à la diffusion de l'urée que le côlon et présente une activité uréasique de la muqueuse légèrement supérieure à celle présente dans le côlon (Aoyagi et al., 1966), l'uréolyse pouvant y être plus marquée (Gibson, Sladen et Dawson, 1973). Mais c'est probablement le gros intestin qui est l'organe le plus concerné dans le métabolisme de l'urée puisque chez l'Homme atteint de cirrhose, l'administration orale d'urée provoque une augmentation de 50 p. 100 de la concentration sanguine d'ammoniaque, alors que la même dose administrée par voie rectale augmente l'ammoniémie de 400 p. 100 (Evans, Aoyagi et Summerskill, 1966).

Quel est le bilan de l'activité de la flore sur le métabolisme de l'urée ? Selon Walser et Bodenlos (1959) la synthèse journalière d'urée dans les tissus chez l'Homme dépasse l'excrétion urinaire d'urée d'environ 20 p. 100, la différence étant due à la dégradation de l'urée dans l'intestin. Après administration d'antibiotiques, la perte urinaire correspond plus étroitement à la synthèse d'urée (Jones et al., 1969). On peut ainsi considérer qu'une quantité de 6 à $9 \mathrm{~g}$ d'urée, soit $20 \mathrm{p}$. 100 de la synthèse uréique journalière, est catabolisée chaque jour dans le tube digestif de l'Homme adulte. Les quantités arrivant de l'iléon sont très faibles, environ $0,4 \mathrm{~g}$ (Gibson, Sladen et Dawson, 1973). Presque toute l'urée recyclée doit ainsi être sécrétée dans le gros intestin, métabolisée et ses métabolites absorbés. Ces métabolites sont constitués par 200$300 \mathrm{mmoles}$ d'ammoniaque, et une quantité moitié moindre de bicarbonate.

L'ammoniaque produite est elle-même absorbée par un processus de diffusion non ionique (Castell et Moore, 1971 ; Bown et al., 1971 ; Down et al., 1972). La présence de bicarbonate en facilite l'absorption, la diffusion de ces deux corps étant couplée (Wrong, 1971).

Chez le Porc, des travaux récents (Rérat ef al., 1979) montrent que le sang efférent intestinal est plus riche en ammoniaque duranf la digestion que le sang artériel (fig. 1), ce qui met en évidence une absorption permanente de ce corps $(15 \mathrm{mmoles} / \mathrm{h}$ environ, soit $300 \mathrm{mg}$ ) ayant tendance à s'accroître avec le temps après l'ingestion du repas, ce qui serait en faveur d'une désamination des résidus alimentaires ; une partie de cette ammoniaque peut également provenir de l'urée sécrétée dans le tube digestif (15 mmoles/h soif $1 \mathrm{~g}$ ) : a contrario plus de la moitié de l'urée sécrétée dans les conditions habituelles d'alimentation dans le tube digestif serait ainsi utilisée pour la synthèse des protéines microbiennes. 


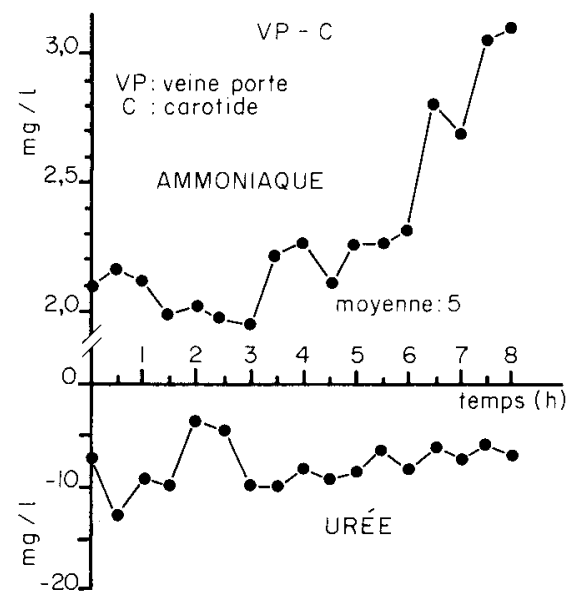

FIG. 1. - Différences portoartérielles des concentrations (VP-C) d'ammoniaque et d'urée. Evolution avec le temps écoulé après le repas (régime semi-synthétique : 14 p. 100 protéines de poisson, amidon de maïs, huile, mélange minéral et vitaminique). Une différence positive (cas de l'ammoniaque) signifie l'enrichissement du sang efférent, c'est-à-dire une absorption. Une différence négative (cas de l'urée) signifie l'appauvrissement du sang afférent, c'est-à-dire une sécrétion.

\subsection{Bilan de la digestion des matières azotées dans le gros intestin.}

Les quantités d'azote fotal ou $\alpha$-aminé susceptibles de disparaître au niveau du gros intestin, déterminées par des expériences de digestibilité segmentaire iléorectale (Holmes ef al., 1974 ; Zebrowska et Buraczewski, 1977) ou par l'étude de l'évolution des contenus digestifs (Mason, Just et Bech-Andersen, 1976) représentent entre 7 et 24 p. 100 de l'azote total absorbé au long du tube digestif ; les variations enregistrées étant liées à la composition du régime (protéines, glucides).

Au plan quantitatif, les bilans de disparition des acides aminés individuels ont été faits (Holmes ef al., 1974). Compte tenu du faible nombre de données actuellement disponibles, il est préférable de ne pas tenir compte des conclusions nutritionnelles de ce type de bilan.

En tout état de cause, il faut rappeler ici les résultats de Zebrowska (1973c, 1975), Zebrowska, Buraczewska et Horaczynski (1977) et de Salter, Coates et Hewitt (1974) montrant le peu de valeur nutritionnelle pour des animaux en croissance des produits azotés absorbés à ce niveau. Il se peut par contre que les phénomènes d'absorption à ce niveau aient une signification pour la conservation ef le recyclage de l'N chez l'animal adulte et chez l'Homme (Richards, 1972).

Quoi qu'il en soit, dans la mesure où les produits absorbés dans la partie postérieure de l'intestin semblent partiellement inutilisables au plan métabolique, dans la mesure également où certains acides aminés plus que d'autres sont fixés dans les microorganismes au cours du transit iléo-rectal, il paraît difficile de se baser sur les données de digestibilité rectale pour définir quelle proportion des acides aminés alimentaires a été absorbée sous une forme utilisable pour la synthèse protéique. Même si ces données de digestibilité apparente sont proches des données définies au niveau iléal pour certaines protéines, elles semblent s'en écarter de façon notable pour d'autres, et ces écarts varient selon la nature de la fraction non protéique du 
régime. Il apparaît ainsi plus fondé d'apprécier la fraction utilisable à partir de la digestibilité iléale apparente. Le fait qu'une partie de l'azote absorbé à ce niveau soit d'origine endogène n'introduit pas d'erreur dans cette appréciation puisque, en raison de l'absence d'une attaque microbienne importante avant la jonction iléale, on peut penser que la totalité de l'azote absorbé dans l'intestin grêle l'est sous forme d'aminoacides, c'est-à-dire sous forme utilisable. Il serait donc urgent de poursuivre les travaux pour définir de façon systématique la digestibilité iléale d'acides aminés en provenance de diverses protéines, ou de mélanges, et leurs facteurs de variation. En l'absence de telles données, il paraît d'une approximation suffisante, non pas de se baser sur la digestibilité rectale apparente ou réelle des acides aminés individuels, essentiellement variable d'une protéine à une autre et selon le contexte nutritionnel, mais d'appliquer à chacun d'entre eux pour une protéine donnée le coefficient de digestibilité apparente des matières azotées totales.

\section{Conclusion.}

Par sa sifuation particulière relativement au reste du tube digestif, le gros intestin participe, d'une façon qui peut être importante, à la digestion des aliments et à l'absorption des nutriments. En raison de la stase de plus ou moins longue durée qui s'y produit, liée à l'accroissement du volume du tube digestif qui y crée de véritables réservoirs, toutes les conditions favorables à une croissance microbienne intense $y$ sont réunies. C'est précisément certains aspects de cette activité microbienne qui ont été examinés dans cette revue et plus particulièrement ceux qui s'adressent à la dégradation des résidus des matières azotées et des sucres qui sont susceptibles d'y parvenir. Ont été laissés de côté des aspects fort importants de l'action digestive du gros intestin, et notamment ceux qui concernent la métabolisation des stérols et des lipides par la flore digestive, la synthèse et l'absorption éventuelle des vitamines $B$ et $K$, et enfin les mouvements d'eau et d'électrolytes.

L'intervention du gros intestin dans la digestion n'a pas la même importance selon qu'elle intéresse les glucides ef les protéines, et semble beaucoup plus efficace pour les premiers que pour les secondes. En effet, qu'il s'agisse de cellulose ou de diholosides dont les résidus non digérés parviennent en quantités élevées dans le gros intestin en raison de leur taux excessif dans le régime, on constate une dégradation bactérienne plus ou moins marquée avec une production d'acides gras volatils. Ce système de récupération est relativement efficace puisque ces produits sont absorbés et utililisés avec un bon rendement au plan métabolique. Cependant, cette dégradation se traduit également par l'apparition de déchets inutilisables tels qu'acide carbonique, hydrogène et méthane dont l'existence vient diminuer le rendement de la dégradation des glucides. Dans l'état actuel des choses, on ne possède que des approximations quant à la formation respective de ces divers produits, ef il y a grand besoin de travaux pour apporter des précisions à ce sujet.

Si la dégradation des sucres non digérés se traduit par l'apparition de divers produits, elle fournit par ailleurs de l'énergie pour la synthèse microbienne. Cette synthèse de protéines microbiennes se fait aux dépens des matières azotées non digérées, d'origine alimentaire ou endogène, qui parviennent à ce niveau. Celles-ci, et particulièrement les matières azotées endogènes, sont dégradées, leurs acides ami- 
nés sont désaminés, ou décarboxylés (avec formation d'amines). L'ammoniaque produite est réutilisée pour la synthèse microbienne et excrétée dans les fèces sous forme de protéines microbiennes, ou absorbée et généralement très faiblement utilisée dans l'organisme pour la synthèse d'acides aminés non essentiels. Cependant, pour les animaux adultes qui ont seulement un besoin d'entretien, ce processus peut être une bonne voie pour recycler l'azote d'origine endogène.

Quoi qu'il en soit, la disparition dans le tube digestif postérieur, que ce soit de glucides ou de matières azotées, concerne 10 à 20 p. 100 de l'ensemble des phénomènes d'absorption tout au long du tube digestif. L'excrétion d'azote dans les microorganismes est généralement en relation directe avec la présence et le taux de sucres à faible digestibilité ou de cellulose dans le régime. Si l'on tient compte de l'utilisation métabolique faible des matières azotées absorbées dans le gros intestin, et prenant en considération leur variation de composition due aux glucides, la signification scientifique et pratique de la digestibilité totale de l'azote devraił être discutée. II faut souligner que la disponibilité des acides aminés déduite des données de digestibilité esł généralement surestimée, l'erreur étant variable selon l'acide aminé considéré. Une question persiste qui concerne l'importance du phénomène de coprophagie pour la réutilisation des protéines microbiennes.

Journées Digestion-Absorption

de l'Association française de Nutrition,

Toulouse-Auzeville, 20-21 novembre 1980.

Ce rapport constitue une actualisation de la revue publiée dans J. anim. Sci., 46, 1808-1837 (1978).

\section{Références}

ALAIS C., JOLLES P., 1964. Etude des substances solubles au cours de la réaction de la présure sur la caséine. Bull. Soc. Chim. biol., 46, 7-8.

ALEXANDER F., DAVIES M. E., 1963. Production and fermentation of lactate by bacteria in the alimentary canal of the horse and pig. J. comp. Pathol., 73, 1-8.

ALVAREZ R. J., LY J., 1975. Some fermentative parameters in crop and caeca of chickens fed on maize or final molasses. Preliminary data. Cuban J. agric. Sci., 9, 49-56.

AOYAGI T., ENGSTROM G. W., EVANS W. B., SUMMERSKILL W. H. J., 1966. Gastrointestinal urease in man. I. - Activity of mucosal urease. Gut, 7, 631-635.

ARGENZIO R. A., SOUTHWORTH M., 1975. Sites of organic acid production and absorption in gastrointestinal tract of the pig. Amer. J. Physiol., 228, 454-460.

AUMAITRE A., 1971. Le développement des enzymes dans le tube digestif du jeune porcelet : importance pour le sevrage et signification nutritionnelle. Ann. Zootech., 20, 551-575.

AUMAITRE A., FÉVRIER C., DEWULF H., 1977. Influence du lactose alimentaire sur le développement de l'activité lactasique dans l'appareil digestif du porc. C. R. Acad. Sci. Paris, Sér. D, 284, 2135-2138.

BAILEY C. B., KITTS W. D., WOOD A. J., 1956. The development of the digestive enzyme system of the pig during its preweaning phase of growth. B. Intestinal lactase, sucrase, and maltase. Can. J. agric. Sci., 36, 51-58.

BAKER F., NASR H., MORRICE F., BRUCE J., 1950. Bacterial breakdown of structural starches and starch products in the digestive tract of ruminant and non-ruminant animals. J. Pathol. Bacferiol., 62, 617-638.

BARCROFT J. R., MCANALLY R. A., PHILLIPSON A. T., 1944. Absorption of volatile acids from the alimentary tract of the sheep and other animals. J. exp. Biol., 20, 120. 
BARNES R. H., KWONG E., 1965. Effect of soybean Trypsin inhibitor and penicillin on cystine biosynthesis in the pancreas and its transport as exocrine protein secretion in the intestinal tract of the rat. J. Nutr., 86, 245-252.

BARRY R. J. C., SMYTH D. H., 1960. Transfer of short-chain fatty acids by the intestine. J. Physiol. (Lond.), 152, 48-66.

BAYLEY H. S., HOLMES J. H. G., STEVENSON K. R., 1974. Digestion by the pig of the energy and nitrogen in dried, ensiled and organic-acid-preserved corn : with observations on the starch content of digesta samples. Can. J. anim. Sci., 54, 377-383.

BELLA A., KIM S. Y., 1972. Rat small intestinal mucin : isolation and characterization of a watersoluble mucin fraction. Arch. Biochem. Biophys., 150, 679-689.

BERGNER H., SIMON O., ZIMMER M., 1975. Effect of natural crude fibre content in rat diets on amino acid absorption, Archiv. Tierernähr., 25, 95-104.

BILLICH C. O., LEVITAN R., 1969. Effects of sodium concentration and osmolality on water and electrolyte absorption from the intact human colon. J. clin. !nvest., 48, 1336-1347.

BINDER H. J., 1970. Amino acid absorption in the mammalian colon. Biochem. biophys. Acta, 219, 503-506.

BOND J. H., LEVITT M. D., 1974. Colonic conservation of carbohydrate (CHO). Clin. Res., 22, $355 \mathrm{~A}$.

BORGSTRÖM B., DAHLQUIST A., GUSTAFSSON B. E., LUNDH G., MALMQUIST J., 1959. Trypsin, invertase and amylase content of feces of germfree rats. Prod. Soc. exp. Biol. Med., 102, 154155.

BOWLAND J. P., YOUNG B. A., MILLIGAN L. P., 1971. Influence of dietary volatile fatty acid mixtures on performance and on fat composition of growing pigs. Can. J. anim. Sci., 51, 89-94.

BOWN R. L., SLADEN G. E., CLARK M. L., DAWSON A. M., 1971. The production and transport of ammonia in the human colon. Gut, 12, 862 (Abstr.).

BREITE S., HEINZ T., MEIER H., POPPE S., 1973. Beeinflussung der aminosaürenresorbierbarkeit durch Verschiedene Faktoren. Proc. 4th int. Symp. on aminoacids, Brno, CSSR, A12.

BROWN C. L., HILL M. J., RICHARDS P., 1971. Bacterial ureases in uraemic men. Lancet, II (1), 406-407.

BURACZEWSKA L., 1979. Secretion of nitrogenous compounds in the small intestine of pigs, Acto physiol. pol., 30, 319-326.

BURACZEWSKA L., BURACZEWSKI S., HORSZCZARUK F., JONES A. S., ZEBROWSKA T., 1975. An attempt to estimate the endogenous nitrogen content in the digesta of pigs fed on diets with proteins containing hydroxyproline. Rocz Nauk Roln. B., 96, 105-114.

BURGET G. E., MOORE P. H., LLOYD R. W., 1933. Absorption of glucose by chronic loops of colon. Amer. J. Physiol., 105, 187-190.

CASTELL D. O., MOORE E. W., 1971. Ammonia absorption from the human colon. The role of nonionic diffusion. Gastroenterology, 60, 33-42.

CHAO F. C., TARVER H., 1953. Breakdown of urea in the rat. Proc. Soc. exp. Biol. Med., 84, 406-409.

CHARLET-LERY G., 1964. Utilization of the energy of lactic acid by the growing pigs. Comparison with starch. Proc. 3rd Symp. on Energy Metabolism, Troon Ayrshire, Scotland, publ 11 E. A. A. P., 279-284. Acad. Press Inc. (London).

CLEMENS E. T., STEVENS C. E., SOUTHWORTH M., 1975. Sites of organic acid production and pattern of digesta movement in the gastrointestinal tract of swine. J. Nutr., 105, 759-768.

COATES M. E., HEWITT S., GOLOB P., 1970. A comparison of the effects of raw and heated soyabean meal in diets for germ free and conventional chicks. Brit. J. Nutr., 24, 213-225.

COMBE E., DEMARNE Y., GUÉGUEN L., IVOREC-SZYLIT O., MESLIN J. C., SACQUET E., 1976. Some aspects of the relationships between gastrointestinal flora and host nutrition. World Rev. Nutr. Dief., 24, 1.57.

COMBE E., PENOT E., CHARLIER H., SACQUET E., 1965. Métabolisme du rat " germfree » Teneurs des contenus digestifs en certains composés azotés, en sodium et en potassium. Teneurs de quelques tissus en acides nucléiques. Ann. Biol. anim. Bioch. Biophys., 5, 189-206.

COMBE E., PION R., 1966. Note sur la composition en arides aminés du contenu de crecum de rats axéniques et de rats témoins. Ann. Biol. anim. Bioch. Biophys., 6, 255-259.

COMBE E., PION R., SACQUET E., 1970. Influence de la nature et du taux des protéines alimenfaires sur la composition en acides aminés du contenu du cæecum du rat axénique. Ann. Biol. anim. Bioch. Biophys., 10, 697-702. 
COMBE E., SACQUET E., 1966. Influence de l'état axénique sur divers composés azotés contenus dans le crecum de rats albinos recevant des quantités variables de protéines. $C$. $R$. Acod. Sci. Paris, Sér. D, 262, 685-688.

COOK G. C., 1967. Lactase activity in newborn and infant baganda. Brit. Med. J., 1, 527-530.

CORDERO N., WILSON T. H., 1961. Comparison of transport capacify of small and large intestine. Gastroenterology, 41, 500-504.

CORRING T., JUNG J., 1972. The amino acid composition of pig pancreatic juice. Nutr. Rep. Int., 6, 187-190.

CRANWELL P. D., NOAKES D. E., HILL K. J., 1976. Gastric secretion and fermentation in the suckling pig. Brit. J. Nutr., 36, 71-86.

CROMPTON D. W. T., NESHEIM M. C., 1969. Amino acid patterns during digestion in the small intestine of ducks. J. Nutr., 99, 43-50.

CUMMINGS J. H., 1975a. Absorption and secretion by the colon. Gut, 16, 323-329.

CUMMINGS J. H., 1975b. The colon : absorptive secretory and metabolic functions. Digestion, 13 , 232-240.

CUMMINGS J. H., HILL M. J., JENKINS D. J. A., PEARSON J. R., WIGGINS H. S., 1976. Changes in fecal composition and colonic function due to cereal fiber. Amer. J. clin. Nutr., 29, 14681473.

CUNNINGHAM H. M., FRIEND D. W., NICHOLSON J. W. G., 1963. Observations on digestion in the pig using a re-entrant intestinal fistula. Con. J. onim. Sci., 43, 215-225.

DAHLQUIST A., 1961. The location of carbohydrases in the digestive tract of the pig. Biochem. J., 78, 282-288.

DAMMERS J., 1964. Digestibility in the pig. Factors influencing the digestion of the components of the feed and the digestibility of the amino acids. Th. Drukkery " West friesland \#, Hoorn, Pp. 152, Univ. van Leuven Landbouvinstitut.

DARCY B., 1980. Contribution à l'éfude de lo digestion dans l'intestin grêle chez le porc : étude de l'interaction entre la nature de l'amidon ef la source proféique du régime. Th. Doct. Ing., Paris, 107 pp.

DAVIDSON J. N., GARRY R. C., 1939. The absorption of monosaccharides from the large intestine of the rat under urethane anaesthesia. J. Physiol., 96, 172-175.

DAWSON A. M., HOLDSWORTH C. D., WEBB J., 1964. Absorption of short chain fatty acids in man. Proc. Soc. exp. Med., 117, 97-100.

DEGAND R., GAVERIAUX M., HAVEZ R., 1972. Définition biochimique des sulfomucines et des sialomucines de l'intestin grêle du porc. C. R. Soc. Biol. Paris, 166, 622-627.

DEGUCHI E., NIIYAMA M., KAGOTA K., NAMIOKA S., 1978. Role of intestinal flora on incorporation of $15 \mathrm{~N}$ from dietary, $15 \mathrm{~N}$-urea and $15 \mathrm{~N}$-diammonium citrate into tissue proteins in pigs. J. Nutr., 108, 1572-1579.

DELORT-LAVAL J., CHARLET-LERY G., ZELTER S. Z., 1963. Efficacité de quelques protides alimentaires chez le porc. IV. - Données complémentaires sur l'action de l'auréomycine sur le métabolisme azoté. Ann. Biol. anim. Bioch. Biophys., 3, 369-380.

DELORT-LAVAL J., CHARLET-LERY G., ZELTER S. Z., MERCIER C., GUILBOT A., $1968 . \quad$ Effect of raw potato starch on $\mathrm{N}$ metabolism in growing pigs. Proc. 2nd World Conf. anim. Prod. (Maryland), 336-337.

DEMAUX G., LE BARS H., MOLLÉ J., RÉRAT A., SIMONNET H., 1961. Absorption des acides aminés au niveau du rumen, de l'intestin grêle et du cæcum chez le mouton. Bull. Acad. vet. Fr., 34, 65-88.

DOWN P. F., AGOSTINI L., MURISON J., WRONG O. M., 1972. The interrelations of faecal ammonia, $\mathrm{pH}$ and bicarbonate : evidence of colonic absorption of ammonia by non-ionic diffusion. Clin. Sci., 43, $101-114$.

DREYER . I. J., CONCAMON T. R. J., de KLERK W. A., 1975. Digestibility of protein and dry matter in caecectomised and intact rats. S. Afr. med. J., 49, 1661-1666.

EGGU.M P. O. 1973. A study of certain factors influencing protein utilization in rats and pigs. Beretn. Forsngs! ab., Copenhague, 406, $173 \mathrm{pp}$.

EKSTROM K. E., BENEVENGA N. J., GRUMMER R. H., 1975a. Effects of diets containing dried whey on the lactase activity of the small intestinal mucosa and the contents of the small intestine and caecum of the pig. J. Nutr., 105, 851-860.

EKSTROM K. E., BENEVENGA N. J., GRUMMER R. H., 1975b. Changes in the intestinal lactase 
activity in the small intestine of two breeds of swine from birth to 6 weeks of age. J. Nutr. 105, $1032-1038$.

ERBERSDOBLER H., 1971. Deamination of undigested proteins and peptides by gut flora. Soc. Nutr. Physiol. Livestock, Z. Tierphysiol. Tierernähr. Futtermitfelk., 27, 217-218.

ERBERSDOBLER H., 1973. The normal course of digestion of food proteins, 453-467. In PORTER J. W. G., ROLLS B. A. Proteins in human nutrition, Acad. Press, London, N. Y.

ERBERSDOBLER H., RIEDEL G., 1972. Estimation of amino acid digestibility in germfree and conventionally housed chickens. Arch. Geflügelk., 36, 218-222.

ERBERSDOBLER H., GROPP J., SCHARRER E., 1972. Zur Methioninwirksamkeit von DL-AcetylMethionin-Calcium. Z. Tierphysiol. Tierernähr. Fuftermittelk., 30, 142-143.

ÉTIENNE M., 1969. Premiers résultats concernant les quantifés d'acides gras volatils et d'acide lactique présentes dans le tube digestif du porc. Journ. Rech. Porcine en France, Paris, I. N. R. A.I. T. P. éd., 131-136.

EVANS W. B., AOYAGI F., SUMMERSKILL W. H. S., 1966. Gastrointestinal urease in man, 11. Urea hydrolysis and ammonia absorption in upper and lower gut lumen and the effect of neomycin. Gut, 7, 635-639.

EWE K., SUMMERSKILL W. H. J., 1965. Transfer of ammonia in the human jejunum. J. lab. clin. Med., 65, 839-847.

EYSSEN H., 1973. Role of the gut microflora in metabolism of lipids and sterols. Proc. Nutr. Soc., 32, $59-63$.

FARRELL D. J., JOHNSON K. A., 1972. Utilization of cellulose by pigs and its effects on caecal function. Anim. Prod., 14, 209-217.

FÉVRIER C., 1969. Utilisation du lactosérum et du lactose par le porc en croissance finition. Journ. Rech. Porcine en France, Paris, I. N. R. A.-I. T. P. ed., 91-98.

FÉVRIER C., COLLET J., BOURDON D., 1973. Utilisation de divers types de lactosérum dans les régimes de sevrage des porcelets et durant la période de croissance finition. Journ. Rech. Porcine en France, Paris, I. N. R. A.-I. T. P. ed., 79-86.

FILLASTRE J. P., BLAISE P., ARDAILLOU R., RICHET G., 1965. Secretion gastrique des urémies chroniques. Rev. fr. Et. clin. biol., 10, 180.

FLESHLER B., GABUZDA G. J., 1965. Effect of ammonium chloride and urea infusions on ammonium levels and acidity of gastric juice. Gut, 6, 349-356.

FOSTER G. L., RITTENBERG D., SCHOENHEIMER R., 1938. Deuterium as an indicator in the study of intermediary metabolism. XIV. Biological formation of deuteroaminoacids. J. biol. Chem., 125, 13-22.

FRANÇOIS A. C., MICHEL M., 1958. Les antibiotiques dans l'alimentation animale. Ann. Nutr. Aliment., 12, 152-161.

FRIEND D. W., CUNNINGHAM H. M., NICHOLSON J. W. G., 1962. The production of organic, acids in the pig. 1. The effect of diet on the proportions of volatile fatty acids in pig feces. Can. J. anim. Sci., 42, 55-62.

FRIEND D. W., CUNNINGHAM H. M., NICHOLSON J. W. G., 1963a. The production of organic acids in the pig. 2. The effect of diet on the levels of volatile fatty acids and lactic acid in sections of the alimentary tract. Can. J. anim. Sci., 43, 156-158.

FRIEND D. W., CUNNINGHAM H. M., NICHOLSON J. W. G., 1963b. Volatile fatty acids and lactic acid in the alimentary tract of the young pig. Can. J. anim. Sci., 43, 174-181.

FRIEND D. W., NICHOLSON J. W. G., CUNNINGHAM H. M., 1964. Volatile fatty acid and lactic acid content of pig blood. Can. J. anim. Sci., 44, 303-308.

GARRER A, H., GROEN J., HALLEN L., 1941. The absorption of glucose from the human rectum Acia med. scand., 107, 1-10.

GEBHARDT G., KÖHLER R., ZEBROWSKA T., 1978. Untersuchungen zur Stickstoff und Aminosäurenresorption beim Schwein 4. Resorption der Amino saüren. Arch. Tierernähr., 28, 603608.

GENELL S., GUSTAFSSON B. E., OHLSSON K., 1976. Quantifation of active pancreatic endopeptidases in the intestinal contents of germfree and conventional rats. Scand. J. Gastroenterol. 11, 757-762.

GIBSON S. A., SLADEN G. E., DAWSON A. M., 1973. Studies in the role of the colon in urea metabolism. Gut, 14, 816 (Abstr.). 
GOMPERTZ D., BROOKS A. P., GAYA H., SPIERS A. S. D., 1973. Volatile fatty acids in the faeces of patients in germ-free isolation. Gut, 14, 183-186.

GRIMSON R. E., BOWLAND J. P., MILLIGAN L. P., 1971. Use of nitrogen 15 labelled urea to study urea utilization by pigs. Can. J. anim. Sci., 51, 103-110.

GUMBMANN M. R., WILLIAMS S. N., 1971. The quantitative collection and determination of hydrogen gas from the rat and factors affecting its production. Prod. Soc. exp. Biol. Med., 137, 11711175.

HARPER A. E., de MUELENAERE H. J. M., 1963. The nutritive value of cereal proteins with special reference to the availability of aminoacids. In Biochem. Principles of the Food Industry, vol. VIII, J. V. B., $28,82$.

HEATON J. W., 1972. Uptake of sugars by mucosa of rat colon. Amer. J. dig. Dis., 17, 7-16.

HECKER J. F., GROVUM W. L., 1975. Rates of passage of digesta and water absorption along the large intestines of sheep, cows and pigs. Austral J. biol. Sci., 28, 161-167.

HELLER M. D., KERN F., 1968. Absorption of lactic acid from an isolated intestinal segment in the intact rat. Proc. Soc. exp. Biol. Med., 127, 1103-1106.

HELLER S. N., RIVERS J. M., HACKLER L. R., 1977. Dietary fiber : the effect of particle size and pH on its measurement. J. Food Sci., 42, 436-439.

HILL H., 1969. Der Ablauf der Verdauung bei den einmägigen Tieren einschliesslich der Mekanik des gesamten Verdauungsapparates. In LENKEIT W., BREIREM K., CRASEMANN E., Handbuch der Tierernährung, 1, 172, Paul Parey, Hamburg und Berlin.

HOLMES J. H. G., BAYLEY H. S., HORNEY F. D., 1973. Digestion and absorption of dry and highmoisture maize diets in the small and large intestine of the pig. Brit. J. Nutr., 30, 401-410.

HOLMES J. H. G., BAYLEY H. S., LEADBEATER P. A., HORNEY F. D., 1974. Digestion of protein in small and large intestine of the pig. Brit. J. Nutr., 32, 479-489.

HORSZCZARUK F., SLJIVOVACKI K., 1966. Decomposition of crude fibre in the caecum and colon of pigs. Rocz. Nouk Rol. (B), 89, 67-71.

HORSZCZARUK F., SLJIVOVACKI K., 1971. Decomposition of crude fibre in the caecum and colon of pigs. 2. Rocz. Nauk Rol (B), 93, 143-147.

HOTZEL D., BARNES R. H., 1966. Contributions of the infestinal microflora to the nutrition of the host. Vitam. Horm., 24, 115-171.

IMOTO S., NAMIOKA S., 1978a. V. F. A. production in the pig large intestine, J. anim. Sci., 47, 467478.

IMOTO S., NAMIOKA S., 1978b. V. F. A. metabolism in the pig. J. anim. Sci., 47, 479-487.

ISSHIKI Y., YOKOTA H., NAKAHIRO Y., TASAKI I., 1974. Digestion and absorption in the caecum of chickens. Jap. J. zoof. Sci., 45, 488-493.

IVAN M., FARRELL D. J., 1976. Nutritional evaluation of wheat. 5. Disappearance of components in digesta of pigs prepared with two re-entrant cannulae. Anim. Prod., 23, 111-119.

JAMES P. S., SMITH M. W., 1976. Methionine transport by pig colonic mucosa measured during early post-natal development. J. Physiol. (Lond.), 252, 151-168.

JONES E. A., SMALLWOOD R. A., CRAIGIE A., ROSENOER V. M., 1969. The enterohepatic circulation of urea nitrogen. Clin. Sci., 37, 825-836.

JUST A., 1980. Ileal digestibility of protein : applied aspects, 66-75. In LOW A. G., PARTRIDGE I. G., Current concepts of digestion and absorption in pigs. Tech. Bull. 3, N. I. R. D., Reading, England.

KAGOTA K., IWASE T., KOJIMA T., NIIYAMA M., NAMIOKA S., 1979. Diammonium citrate addition to a diet restricted non essential aminoacids for young pigs. Jap. J. vet. Sci., 41, 131-138.

KEYS J. E. Jr. 1972. Hemicellulose, cellulose and starch digestion in, and the rate of passage of digesta through the stomach, small intestine and large intestine of swine, Diss. Abstr. int., B. 33,6 .

KEYS J. E. Jr., DE BARTHE J. V., 1974a. Cellulose and hemicellulose digestibility in the stomach small intestine and large intestine of swine. J. anim. Sci., 39, 53-56.

KEYS J. E., Jr., DE BARTHE J. V., 1974b. Site and extent of carbohydrate, dry matter, energy and protein digestion and the rate of passage of grain diets in swine. J. anim. Sci., 39, 57-62.

KEYS J. E. Jr., VAN SOEST P. J., YOUNG E. P., 1970. Effect of increasing dietary cell wall content on the digestibility of hemicellulose and cellulose in swine and rats. J. anim. Sci., 31, 11721177.

KIDDER D. E., MANNERS M. J., 1978. Digestion in the pig. Scientechnica, Bristol, pp. 201. 
KIM K. I., BENEVENGA N. J., GRUMMER R. H., 1978a. Lactase activity and VFA production in the caecum and colon of pigs fed a corn-soy or 40 p. 100 whey diet. J. anim. Sci., 46, 1648-1657.

KOCH G., LEDINEK M., GIESECKE D., 1972. The participation of microorganisms in digestive metabolism of pigs. 1. Studies on slaughter pigs. Z. Tierphysiol. Tierernähr. Futtermiffelk., 30, 222-231.

KÖHLER R., ZEBROWSKA T., GEBHARDT G., 1978. Untersuchungen zur Stickstoff und Amino säurenresorption beim Schwein 3. Mitteilung : Endogene Ausscheidung und Resorption des Stickstoffs. Arch. Tierernähr., 28, 317-327.

KOLDOVSKY O., CHYTIL F., 1965. Postnatal development of $\beta$-galactosidase activity in the small intestine of the rat. Effect of adrenalectomy and diet. Biochem. J., 94, 266-270.

KUIKEN K. A., 1952. Availability of the essential aminoacids in cottonseed meal. J. Nutr., 46, 13-25.

KUIKEN K. A., LYMAN C. M., 1948. Availability of aminoaciu's in some foods. J. Nutr., 36, $359-368$.

LARSON N. L., HILL E. G., 1960. Aminoformation and metabolic activity of microorganisms in the ileum of young swine fed chlortetracycline. J. Bact., 80, 188-192.

LAURENTOWSKA C., 1959. The ability of swine to digest the components of crude fibre (lignin, cellulose, pentosans). Rocz. Nauk, roln. (B), 74, 567-576.

LEDINEK M., 1970. Role of micro-organisms in digestion of raw and cooked potatoes by pigs. Diss. Tierärztl. Fak. Ludwig-Maximilians-Univ. München, Fed. Germ. Rep. $v+101$ pp.

LEVITT M. D., BERGGREN T., HASTINGS J., BOND J. H., 1974. Hydrogen $\left(\mathrm{H}_{2}\right)$ catabolism in the colon of the rat. J. lab. clin. Med., 84, 163-167.

LINDSTEDT G., LINDSTEDT J., GUSTAFSSON B. E., 1965. Mucus in intestinal contents of germ free rats. J. exp. Med., 121, 201-213.

LIVINGSTONE R. M., ATKINSON T., BAIRD B., CROFTS R. M. J., 1977. The effect of processing potatoes on the apparent digestion by pigs of organic matter and nitrogen measure overall and at the terminal ileum. Proc. Nutr. Soc., 36, 58A.

LIU C. H., HAYS V. W., SVEC J., CATRON D. V., ASTHON G. C., SPEER V. C., 1955. The fate of urea in growing pigs. J. Nutr., 57, 241-247.

LOESCHE W. J., 1968a. Protein and carbohydrate composition of caecal contents of gnotobiotic rats and mice. Proc. Soc. exp. Biol. Med., 128, 195-199.

LOESCHE W. J., 1968b. Accumulation of endogenous protein in the caecum of the germfree rat.. Proc. Soc. exp. Biol. Med., 129, 380-384.

LONG C. L., GEIGER J. W., KINNEY J. M., 1967. Absorption of glucose from the colon and rectumMetabolism, 16, 413-418.

LOW A. G., 1979. Studies on digestion and absorption in the intestines of growing pigs. 6. Measurements of the flow of aminoacids. Brit. J. Nutr., 41, 147-156.

LUDVIGSEN J. B., THORBEK G., 1961. Fermentation processes in the caecum of pigs. Proc. 8th inf. Congr. Anim. Prod., Hamburg, 267-268.

LY J., 1974. Caecal function in the pig : VFA content and utilization by the caecal wall. Cuban J. agric. Sci., 8, 247-254.

MCATEE J. W., LITTLE C. O., MITCHELL G. E. Jr., 1967. Volatile fatty acids and utilization by rats. J. anim. Sci., 26, 215 (Abstr.).

MCCLYMONT G. L., 1951. Identification of the volatile fatty acid in the peripheral blood and rumen of cattle and the blood of other species. Ausfr. J. agr. res., 2, 92-103.

MCNEAL W. J., LATZER L. L., KERR J. E., 1909. The fecal bacteria of healthy men. Part I. Introduction and direct quantitative observation. J. Inf. Dis., 6, 123.

MANGOLD E., 1934. The digestion and utilization of crude fibre. Nuir. Abstr. Rev., 3, $647-656$.

MANNERS M. J., 1976. The development of digestive function in the pig. Proc. Nutr. Soc., 35, 49-55.

MANNERS M. J., STEVENS J. A., 1972. Changes from birth to maturity in the pattern of distribution of lactase and sucrase activity in the mucosa of the small intestine of pigs. Brit. J. Nutr., 28, 113-127.

MASON V. C., 1969. Some observations on the distribution and origin of nitrogen in sheep faeces. J. agr. Sci. Camb., 73, 99-111.

MASON V. C., JUST A., 1976. Bacterial activity in the hind gut of pigs. I. - Its influences on the apparent digestibilify of dietary energy and fat. Z. Tierphysiol. Tierernähr. Futfermitfelk., 36, 301. 310.

MASON V. C., JUST A., BECH-ANDERSEN S., 1976. Bacterial activity of the hind gut of pigs. 2. Its 
influence on the apparent digestibility of nitrogen and aminoacids. Z. Tierphysiol. Tierernähr. Fuftermittelk., 36, 310-324.

MASON V. C., PALMER R., 1973. The influence of bacterial activity in the alimentary canal of rats on faecal nitrogen excretion. Acia agr. scand., 23, 141-150.

MENDES PEREIRA E., PION R., PRUGNAUD J., 1977. Utilisation digestive apparente des acides aminés de quelques aliments chez le rat en croissance. Ann. Biol, anim. Bioch. Biophys., 17, 625-631.

MICHEL M. C., 1961a. Activité métabolique de la flore tofale isolée de l'intestin du porc. Ann. Biol. anim. Bioch. Biophys., 1, 16-28.

MICHEL M. C., 1961 b. Métabolisme de la flore intestinale du Porc. Influence de la chlortetracycline sur le catabolisme du glucose. Ann. Biol. anim. Bioch. Biophys., 1, 213-221.

MICHEL M. C., 1965. Comparaison de l'action de l'acrylate de sodium et de la chlortétracycline sur la flore intestinale du porc. Ann. Biol. anim. Bioch. Biophys., 5, 223-236.

MICHEL M. C., 1966. Métabolisme de la flore intestinale du porc. Dégradation des formes $L$ et $D$ des acides aminés. Ann. Biol. anim. Bioch. Biophys., 6, 33-46.

MICHEL M. C., JOUANDET C., SALMON-LEGAGNEUR E., AUMAITRE A., FRANÇOIS A. C., 1964. Influence de l'acrylate de sodium sur la croissance du porcelet. Ann. Zoofech., 13, 341-350.

MITCHELL H. H., HAMILTON T. S., 1933. True and apparent digestibility of oat hulls and alfalfa meal by swine with special reference to the ability of swine to digest cellulose and crude fiber. J. ogr. Res., 47, 425-435.

NEWTON C. A., BENNETT A. N., BILLINGS J. A., MILTON-THOMPSON G. F., 1972. lleal short chain fatty acid concentrations after a chemically defined meal. Arch. Mal. Appar. dig., 61, 37c. (Abstr.).

NIIYAMA M., DEGUCHI E., KAGOTA K., NAMIOKA S., 1978. A ppearance of 15N-labeled intestinal microbial aminoacids in the venous blood of the pig colon. Amer. J. vef. Res., 40, 716-718.

NUTTAL G. H. F., THIERFELDER H., 1896. Thierisches Leben ohne Bakterien im Verdauungskanal. II. Mitteilung. Z. Physiol. Chem., 22, 62-72.

OCHOA-SOLANO A., GITLER C., 1968. Digestion and absorption of ingested and secreted proteins labeled with ${ }^{75} \mathrm{Se}$-selenomethionine and ${ }^{35} \mathrm{~S}$-methionine in the gastrointestinal tract of the rat. J. Nutr., 94, 249-255.

PARSONS D. S., PATERSON C. R., 1965. Fluid and solute transport across rat colonic mucosa. Quart. J. exp. Physiol., 50, 220-231.

PAYNE W. L., COMBS G. F., KIFFER R. R., SNYDER D. G., 1968. Investigation of protein quality. lleal recovery of amino acids. Am. Inst. Nutr. 33rd inform. Poult. Nutr. Conf., 52 nd annu. Meet. Fed. am. Soc. exp. Biol., Atlantic City, N. J., April 1968. Fed. Proc., 27, 1199.

PION R., PATUREAU-MIRAND P., COMBE E., MENDES-PEREIRA E., 1977. The digestibility of aminoacids of different feeds for rats, lambs, and non ruminating calves. Proc. 2nd int. Symp. on protein metabolism and nutrition, Flevohof (Netherlands). EAAP publ. no 22, 76-78, PUDOC, Wageningen.

POIJARVI I., 1944. Digestion and utilization of wood cellulose by pigs. Acta agr. Fenn., 57, 1-53.

POPPE S., MEIER H., 1977. Assessment of true digestibility of aminoacids and its value in swine. Proc. 2nd int. Symp. on protein metabolism and nutrition. Flevohof, Netherlands, EAAP publ. $n^{\circ} 22,79-81$. Pudoc Wageningen.

POPPE S., MEIER H., BENNKE H. J., 1977. Zu einigen methodischen Problemen der Bestimmung der wahren Verdaulichkeit von aminosaüren beim Schwein. Proc. 5th int. Symp. on aminoacids, Budapest, 1977, $C_{2}$.

REDDY B. S., WOSTMANN B. S., 1966. Infestinal disaccharidase activity in growing germfree and conventional rats. Arch. Biochem. Biophys., 113, 609-616.

REDDY B. S., PLEASANTS J. R., WOSTMANN B. S., 1968. Effect of dietary carbohydrates on intestinal disaccharidases in germfree and conventional rats. J. Nutr., 95, 413-419.

RÉRAT A., 1964. Rôle de la flore digestive dans la production des vitamines chez les monogastriques et les polygastriques. Ann. Nutr. Aliment, XVIII, C187-C265.

RÉRAT A., 1978. Digestion and absorption of carbohydrates and nitrogenous matters in the hindgut of the omnivorous non ruminant animal. J. anim. Sci., 46, 1808-1837.

RÉRAT A., 1981. Verdauung und Stoffwechsel von Kohlenhydraten und Proteinen in Dickdarm von Omnivoren. Übers. Tierernähr. (sous presse).

RÉRAT A., AUMAITRE A., VAISSADE P., VAUGELADE P., 1976. Absorption of digestion products 
of some holosides : quantitative measurement by studying the portoarterial differences and the portal blood flow rate in the pig. Proc. 4th int. Congr., int. Pig. Vet. Soc., $\mathrm{A}_{12}$, Ames, lowa.

RÉRAT A., BOURDON D., 1972. Valeur nutritive de l'urée comme source d'azole indifférenciée chez le porc en croissance-finition. Journ. Rech. Porcine en France, 4, 185-190, I. N. R. A.I. T. P. éd.

RÉRAT A., BOURDON D., 1974. Valeur nutritive de l'urée comme source d'azole indifférenciée en présence ou non de lactose chez le porc en croissance-finition. Journ. Rech. Porcine en France, 6, 175-185, I. N. R. A.-I. T. P. ed.

RÉRAT A., CORRING T., LAPLACE J. P., 1978. Quelques aspects des recherches en physiologie digestive chez le porc : applications possibles. Journ. Rech. Porcine en France, 95-119, Paris, I. N. R. A.-I. T. P. ed.

RÉRAT A., LISOPRAWSKI C., VAISSADE P., VAUGELADE P., 1979. Métabolisme de l'urée dans le tube digestif du porc: données préliminaires qualitatives et quantitatives. Bull. Acad. vet. Fr., 52, 333-346.

RÉRAT A., POULLAIN F., JACQUOT R., 1958. Rôle nutritionnel des antibiotiques dans le comportement du rat placé successivement en régime protéiprive et en réplétion azotée Ann. Nutr. Aliment., 12, 27-34.

RICHARDS P., 1972. Nutritional potential of nitrogen recycling in man. Amer. J. clin. Nutr., 25, 615625.

RITTENBERG D., SCHOENHEIMER R., KESTON A. S., 1939. Studies in protein metabolism IX. The utilization of ammonia for normal rats on a stock diet. J. biol. Chem., 128, 603-607.

ROSE W. C., DEKKER E. E., 1956 . Urea as a source of nitrogen for the biosynthesis of aminoacids. J. biol. Chem., 223, 107-121.

RUBINSTEIN R., HOWARD A. V., WRONG O. M., 1969. In vivo dialysis of faeces as a method of stool analysis. 4. The organic anion component. Clin. Sci., 37, 549-564.

SALLEE V. L., DIETSCHY J. M., 1973. Determinants of intestinal mucosal uptake of short and medium chain fatty acids and alcohols. J. Lipid Res., 14, 475-484.

SALTER D. N., COATES M. E., 1970. Influence of gut microflora on digestion of proteins on chicks. Proc. int. Congr. Nutr., VIII, Prague, août 1969, 425-429. Excerpta med., Amsterdam.

SALTER D. N., COATES M. E., 1971. The influence of the microflora of the alimentary tract on protein digestion in the chick. Brit. J. Nutr., 26, 55-69.

SALTER D. N., FULFORD R. J., 1974. The influence of the gut microflora on the digestion of dietary and endogenous proteins : studies of the amino acid composition of the excreta of germ-free and conventional chicks. Brit. J. Nufr., 32, 625-637.

SALTER D. N., COATES M. E., HEWITT D., 1974. The utilization of protein and excretion of uric acid in germfree and conventional chicks. Brit. J. Nutr., 31, 307-318.

SALTER D. N., COATES M. E., WESTGARTH D. R., 1971. Studies on the incorporation of ${ }^{14} \mathrm{C}$ labelled aminoacids into egg proteins. Brit. Poult Sci, 12, 483-498.

SAMBROOK I. E., 1979. Studies on digestion and absorption in the intestines of growing pigs, 8. Measurements of the flow of total lipid, acid detergent fibre and volatile fatty acids. Brit. J. Nutr., 42, 279-287.

SAUER W. C., 1976. Factors affecting aminoacid availabilities for cereal grains and their components for growing monogastric animals. Ph. D. Thesis, Univ. Manitoba, Canada.

SCHAFFER J., WALCHER D., LOVE W., BREIDENBACH C., TREXLER P., ASHMORE J., 1965. Studies on fatal hypoglycemia in axenic (germfree) piglets. Proc. Soc. exp. Biol. Med., 118, 566-570.

SHEARER I. J., DUNKIN A. C., 1968a. Lactose utilization by the growing pig. N. Z. J. agric. Res., 11, 465-476.

SHEARER I. J., DUNKIN A. C., 1968b. Caecum enlargement in the lactose-fed pig. N. Z. J. agric. Res., 11, 923-926.

SHEARER I. J., DUNKIN A. C., 1969. Urinary and faecal sugar losses in growing pigs fed diets confaining lactose. N. Z. J. agric. Res., 12, 321-332.

SIDDONS R. C., COATES M. E., 1972. The influence of the intestinal microflora on disaccharidase activities in the chick. Brit J. Nutr., 27, 101-112.

SIMIC V., ILIC A., 1976. Essential Morphological-Topographical differences and characteristics of the caecum in man and domestic animals. Acta anat., 94, 299-310. 
SIMONNET H., LE BARS H., MOLLÉ J., 1957. Le cycle de l'urée administrée par voie buccale chez les ruminants. C. R. Acad. Sci. Paris, 244, 943-945.

SMITH H.W., 1961. The development of the bacterial flora in the faeces of animals and man; the changes that occur during ageing. J. appl. Bact., 24, 235-241.

SMITH M. W., JAMES P. S., 1976. Amino acid transport by the helicoidal colon of the new-born pig. Biochem. biophys. Acto, 419, 391-394.

SNOOK J. T., MEYER J. H., 1964. Response of digestive enzymes to dietary proteins. J. Nutr., 82, 409-414.

SNYDERMAN S. E., HOLT L. E. Jr., DANCIS J., ROITMAN E., BOYER A., BALIS M. E., 1962. "Unessential " nitrogen : a limiting factor in human growth. J. Nutr., 78, 57-72.

SOEST P. J. van, 1973. The uniformity and nutritive availability of cellulose. Fed. Proc., 32, $1804-1808$.

SUMMERSKILL W. H. J., WOLPERT E., 1970. Ammonia metabolism in the gut. Amer. J. clin. Nutr., 23, 633-639.

TRAUTMANN A., ASHER T., 1941. Zur Frage der Zellulozeverdauung. Ein Beitrag zum Abbau der Zellulose im Blinddarm und Kolon des Schweines. Tierernährung, 13, 545-556.

TRAUTMANN A., ASHER T., 1942. Uber die Verdauung Künstlicher und pflanzlicher Zellulosepräparate im Blinddarm des Schweines. Tierernährung, 14, 353-374.

VARTIOVAARA U., ROINE P., 1942. Zur mikrobiologie der Zellulose-verdaung beim Schwein. J. Sci. Agri. Soc. Finland, 14, 127-146.

VERMOREL M., 1968. Utilisation énergétique de la triacétine par le rat en croissance. Ann. Biol. anim. Bioch. Biophys., 8, 453-455.

WALSER M., BODENLOS L. J., 1959. Urea metabolism in man. J. clin. Invest., 38, 1617-1626.

WARREN K. S., NEWTON W. L., 1959. Portal and peripheral blood ammonia concentrations in germfree and conventional guinea pigs. Amer. J. Physiol., 197, 717-720.

WERNER I., 1953. Studies on glycoprotein from mucous epithelium and epithelial secretions. Acta soc. med. Upsal., 58, 1-55.

WHELAN W. J., NASR H., 1951. The amylase of Clostridium butyricum. Biochem. J., 48, 416-422.

WHITT D. D., DEMOSS R. D., 1975. Effect of microflora on the free aminoacid. Distribution in various regions of the mouse gastrointestinal tract. Appl. Microbiol, 30, 609-615.

WILSON D. R., ING T. S.. METCALFE-GIBSON A., WRONG O. M., 1968. The chemical composition of faeces in ureamia, as revealed by in vivo faecal dialysis. Clin. Sci., 35, 197-209.

WINDMUELLER H. G., SPAETH A. E., 1978. Identification of ketone bodies and glutamine as the major respiratory fuels in vivo for postabsorptive rat small intestine. J. biol. Chem., 253 , 69-76.

WOLPERT E., PHILLIPS S. F., SUMMERSKILL W. H. J., 1971. Transport of urea and ammonia production in the human colon. Lancet, ii (7739), 1387-1390.

WORTHINGTON B. S., ENWONWU C., 1975. Absorption of intact protein by colonic epithelial cells of the rat. Amer. Dig. Dis., 20, 750-763.

WOSTMANN B. S., BRÜCKNER-KARDOSS E., 1959. Development of cecal distension in germfree baby rats. Amer. J. Physiol., 197, 1345-1346.

WRONG O. M., 1971. The role of the human colon in homeostasis. Sci. Basis Med. Ann. Rev., PP. 192215.

WRONG O. M., HOUGHTON B. J., RICHARDS P., WILSON D. R., 1970. The fate of intestinal urea in normal subjects and patients with uraemia. In Urea and the kidney. Excerpta med. Congr. Ser., 195, 471.

YANG M. G., BERGEN W. G., SCULTHORPE A. E., MICKELSEN O., 1972. Utilization of ${ }^{14} \mathrm{C}$ labeled E. coli by the rat cecum and after forcefeeding. Proc. Soc. exp. Biol. med., 139, 1312-1316.

YANG M. G., MANOHARAN K., MICKELSEN O., 1970. Nutritional contribution of volatile fatty acids from the caecum of rats. J. Nutr., 100, 545-550.

YOSHIDA T., PLEASANTS J. R., WOSTMANN B. S., 1972. The pH values and nitrogen fractionations of cecal contents and feces of germfree and conventional rabbits. Jap. J. Zoot. Sci., 43, 284-285.

ZEBROWSKA T., 1973a. Influence of dietary protein source on the rate of digestion in the small infestine of pigs. 1. Amount and composition of digesta. Rocz. Nouk. Roln. (B.), 95, 115-133,

ZEBROWSKA T., 1973b. Influence of dietary protein source on the rate of digestion in the small intestine of pigs. 2. The rate of protein digestion and amino acid absorption. Rocz. Nauk. Roln. (B.), 95, 135-155. 
ZEBROWSKA T., 1973c. Digestion and absorption of nitrogenous compounds in the large intestine of pigs. Rocz. Nauk. Roln. (B.), 95, 85-90.

ZEBROWSKA T., 1975. The apparent digestibility of nitrogen and individual aminoacids in the large intestine of pigs. Rocz. Nauk. Roln. (B.), 97, 117-123.

ZEBROWSKA T., BURACZEWSKI S., 1977. Digestibility of aminoacids along the gut of pigs. Proc. 2 nd int. Symp. on protein metobolism and nutrition, Flevohof (Netherlands). EAAP publ. no 22 , 82-85. Pudoc. Wageningen.

ZEBROWSKA T., BURACZEWSKA L., HORACZYNSKI H., 1977. Apparent digestibility of nitrogen and aminoacids and utilization of protein given per os or to the cecum in pigs. 5 th int. Symp. on aminoacids, $\mathrm{C}_{3}$ Budapest.

ZEBROWSKA T., SIMON O., MUNCHMEYER R., BERGNER H., 1976. Studies on the aminoacid absorption and the secretion of endogenic aminoacids into the gastrointestinal tract of pigs. Arch. Tierernähr., 26, 69-82. 